\title{
LOS MARQUESES DE VALDECARZANA, SEÑORES DE VASALLOS EN LA ASTURIAS DEL ANTIGUO RÉGIMEN (SIGLOS XVI-XVIII)
}

\author{
Juan DIAZ ÁLVAREZ \\ Universidad de Oviedo
}

\begin{abstract}
Resumen
El estudio de la nobleza constituye un objetivo esencial en el conocimiento de la realidad histórica peninsular a lo largo de la Edad Moderna, dada su preeminencia social, política y económica. Nuestro estudio se centrará en la privatización del gobierno de determinados espacios constituidos en cotos o jurisdicciones por parte de la nobleza. En este sentido nos centraremos en una familia determinada: los Miranda, marqueses de Valdecarzana. Se pretende observar su evolución en el ascenso social, político y económico. Nos centraremos en su acumulación de señoríos en la Asturias de la Edad Moderna, junto a lo que observaremos su gestión, dando una visión de los titulares de la Casa de Miranda, en tanto y cuanto señores de vasallos.
\end{abstract}

Palabras clave: propiedad señorial, nobleza, Asturias, Antiguo Régimen.

\begin{abstract}
The study of aristocracy, owing to its social, political and economical importance, is an essential aim for the knowledge of the historical reality peninsular during the Modern Age. In this article, we will study the how and the why the nobility makes a process of accumulation of seigniories. In this case, we will outline an important asturian family: the Mirandas, what got the title of nobility of marquises of Valdecarzana, and were the masters of the household of Miranda and one of the most important masters of vassals in Asturias during the Ancient Regime.
\end{abstract}

Key words: Lordly Property, Nobility, Asturias, Ancient Regime. 
A mediados del siglo XVIII, según el catastro de Ensenada, el marqués de Valdecarzana fue el mayor poseedor de vasallos y de cotos jurisdiccionales de Asturias! Le seguían en importancia otros miembros destacados de la aristocracia del Principado. ¿Cómo pudieron concentrar tal número de vasallos y de jurisdicciones?, ¿qué beneficios obtuvieron de ello? A lo largo de nuestro trabajo intentaremos dar respuesta a estos interrogantes.

Este artículo se centra en el estudio y evaluación del patrimonio señorial -desde una óptica económica y social- de una de las más importantes familias nobiliarias de la Asturias de la Edad Moderna. Nos referimos a la Casa de Miranda, que desde 1639 se intitularon vizcondes de Villanueva del Infantazgo y, a partir de 1642, marqueses de Valdecarzana. El proceso de concentración de la propiedad señorial que llegaron a acumular se desarrolló principalmente a lo largo del siglo XVI, consolidándose en las centurias ulteriores.

Las fuentes en que nos basamos para establecer una panorámica básica de la organización del territorio señorial de la Casa de Miranda son los diversos apeos de bienes y libros de rentas mandados hacer por los titulares del mayorazgo a lo largo del periodo cronológico estudiado (siglos XVI-XVIII). Las fuentes del archivo, conservado en el Real Instituto de Estudios de Asturianos (A.R.I.D.E.A.), no nos permitieron hacer una evolución económica de cada uno de los cotos estudiados. No obstante, el material del que nos hemos servido es válido para establecer un panorama general.

La información la completamos con diversa documentación emanada de la familia y localizada en la sección de Protocolos de Oviedo del Archivo Histórico de Asturias (A.H.A.); así como con otros materiales de los archivos de la Casa localizados en las secciones de Nobleza, Estado y Consejos del Archivo Histórico Nacional (A.H.N.); en la sección de Pleitos Civiles del Archivo de la Chancillería de Valladolid (A.Ch.V.) y en el Registro General del Sello (R.G.S.) del Archivo General de Simancas (A.G.S.).

\section{INTRODUCCIÓN}

El coto o jurisdicción supuso un espacio de poder concentrado en manos privadas. Así, el señor se alzó como la única autoridad, gozando de plenos poderes al reglamentar de forma arbitraria las vidas de los habitantes y el territorio de estos espacios geográficos concretos. La titularidad de un señorío supuso una estrategia de ascenso social, imprimiendo prestigio a su poseedor, en tanto y cuanto fue señor de vasallos.

Si bien es cierto que la propiedad señorial fue una de las características de la sociedad y economía de la España del Antiguo Régimen, la historiografía incidió en su problemática a través de diversos estudios. De este modo contamos con estudios

1. Anes Álvarez de Castrillón, G.: Los señorios asturianos, Gijón, 1989, p. 28. Diaz Álvarez, J.: «Aproximación al patrimonio económico de la oligarquia municipal ovetense en el tránsito de los siglos XVI al XVII», en FAYA Díaz, M". A. (Coord.): La nobleza en la Asturias del Antiguo Régimen, Oviedo, 2004 , pp. 96 y s. 
metodológicos clásicos Moxó ${ }^{2}$; desde un punto de vista jurídico contamos con la obra de Guilarte ${ }^{3}$. En los últimos años se tendió a la realización de estudios monográficos de diversas casas aristocráticas castellanas, utilizando una visión de estudios diacrónica ${ }^{4}$.

La historiografía asturiana adolece de estudios que traten el señorío en la región. Los pocos estudios realizados se centran más de forma preferente, en el arco cronológico de la Edad Media ${ }^{5}$, que en el de Moderna ${ }^{6}$. Sobre esta época no se ha tratado lo suficiente la cuestión, y las tesis que la abordan se basan en la poca importancia que tuvo el fenómeno señorial en la región, centrándose en las escasas cargas contributivas de los vasallos, además de la escasa población sometida a la jurisdicción privada, bien civil o eclesiástica ${ }^{7}$.

2. Moxó, S. de: «Las desamortizaciones eclesiásticas del siglo XVI», en Anuarios de Historia del Derecho Español, XXX, 1961 y «Los señorío. En torno a una problemática para el estudio del régimen señorial», en Hispania, 94-95, 1973. En los últimos años el tema metodológico ha sido abordado de nuevo desde ópticas nuevas, vid. Atienza LóPez, A., Serrano Martín, E.: «La propiedad de la tierra en España en la Edad Moderna: propuestas para un debate», en Sarasa Sánchez, E., Serrano Martín, E. (eds.): Señorío y feudalismo en la Península Ibérica, Zaragoza, 1993, pp.197-221; BEnítez SÁNCHEZ-BLANCO, R.: «Nobleza y señorío: el método», en Cuadernos de Historia Moderna, 15, 1994, pp. 375-396.

3. GUILARTE, A. M.: El régimen señorial en el siglo XVI, Valladolid, 1987.

4. Vid. Y UN CASALILLA, B.: «Aristocracia, señorío y crecimiento económico en Castilla: algunas reflexiones a partir de los Pimentel y los Enríquez (siglos XVI y XVII)», en Revista de Historia Económica, 3, 1982, pp. 443-467; ATIENZA HERNÁNDEZ, I.: Aristocracia, poder y riqueza en la España moderna. La Casa de Osuna, siglos XV-XIX, Madrid, 1987; CARRASCo MARTínEZ, A.: El régimen señorial en la Castilla moderna: las tierras de la Casa del Infantazgo en los siglos XVII y XVIII, Madrid, 1991; BAZ VICENTE, $\mathrm{M}^{\prime}$. J.: Señorio y propiedad foral de la alta nobleza en Galicia, siglos XVI-XX. La Casa de Alba, Madrid, 1996; Garcia HeRnán, D.: Aristocracia y señorio en la España de Felipe ll: la Casa de Arcos, Granada, 1999; Valencia Rodriguez, J. M.: Señores de la tierra. Patrimonio y rentas de la Casa de Feria. Siglos $X V-X V I I$, Mérida, 2000.

5. Se destacan sobre todo los estudios de RUIZ DE LA PEÑA SOLAR, J. I.: «Esquema para el estudio de un señorío eclesiástico medieval: jurisdicción de la mitra ovetense en el siglo XIV», en Actas de las $I$ Jornadas de Metodología Aplicada a las Ciencias Históricas, II, Santiago, 1973; «El coto de Leitariegos. Una comunidad de montaña en la Asturias medieval», en Asturiensia Medievalia, 3, 1979. Centrado en el señorío de las órdenes militares contamos con el estudio de BENITO RUANO, E.: «La orden de Santiago en Asturias», en Asturiensia Medievalia, 2, 1975. Con referencia a los señoríos eclesiásticos medievales asturianos vid. TORRENTE FERNÁNDEZ, $\mathrm{M}^{\mathrm{a}}$. I.: El dominio del monasterio de San Bartolomé de Nava (siglos XIIl-XVI), Oviedo, 1982; SUÁrez BELTRÁN, S.: El cabildo de la catedral de Oviedo en la Edad Media, Oviedo, 1986.

6. Junto a otros estudios que expondremos más adelante, contamos el trabajo de PRIETO BANCES, R.: «Apuntes para el estudio del señorío de Santa María de Belmonte en el siglo XVI», en IDEM: Obra escri$t a, 2$ vols., Oviedo, 1976, que se centra en el periodo de transición de la Edad Media a la Moderna.

7. En las postrimerías del siglo XVI la población asturiana sometida al señorio jurisdiccional apenas supuso el $10 \%$, así como el $30 \%$ del territorio regional, porcentajes que se mantuvieron, con alguna ligera variación, mediada la décimo octava centuria. [ANES ÁlVAREZ DE CASTRILlón, G.: Los señorios asturianos..., pp. 19 y ss.; BARreiro MALlón, B.: «Aspectos socio-económicos de Asturias en la Edad Moderna», RAMAllo AsEnsio, G. (coord.): Arquitectura señorial en el norte de España, Oviedo, 1993, p. 20.] 
Los estudios sobre la temática señorial centrados en Asturias son escasos. Contamos con las obras de Anes ${ }^{8}$ y de Faya Díaz. El primero incide en la situación de la realidad señorial en la Asturias de mediados del siglo XVIII utilizando como fuente de estudio el Catastro de Ensenada; si bien estableció una visión general sobre el fenómeno y describe y analiza la situación de los señoríos a través de los datos de Ensenada. Por su parte, la segunda estudia aspectos básicos para el conocimiento de los señoríos eclesiásticos asturianos $\mathrm{y}$, sobre todo, los cambios habidos en el siglo XVI.

\section{LA CASA DE MIRANDA}

La evolución de la Casa de Miranda fue fruto del triunfo de una serie de estrategias socio-económicas a lo largo de la Edad Moderna. El linaje, originario de la montaña occidental asturiana (Teverga), acentuó su presencia de forma paulatina en los concejos periféricos y en otros que les permitieron expandirse hacia el centro de la región. Para ello no se dudó en realizar alianzas matrimoniales ventajosas con linajes del mismo concejo o de otros cercanos - en todo caso con destacados linajes asturianos--, estableciendo una política matrimonial endogámica, que permitió a la familia ampliar sustancialmente su patrimonio económico.

En el ascenso social de los Miranda podemos observar tres claras políticas de tipo matrimonial. En un primer momento, en las postrimerías del siglo XV y albores del XVI, hay una tendencia a establecer matrimonios con miembros de la nobleza cercana a su lugar asentamiento, sobre todo de la montaña occidental asturiana o con sus parientes los Quirós. Según avanza la centuria hay un interés por expandir la influencia del linaje hacia el centro de la región, enlazando con familias que tienen intereses económicos en concejos como Grado, Salas o Pravia, incluso en la línea de costa, como Avilés.

Esta tendencia se observó sobre todo en el siglo XVI y con referencia a los mayorazgos de la Casa. Lope de Miranda († c. 1525) casó con Urraca de Ron, miembro de un destacado linaje de la montaña occidental asturiana, quien aportó un importante patrimonio a través de su dote ${ }^{10}$. Fueron éstos los primeros poseedores del mayorazgo creado por el padre de Lope, Diego Fernández de Miranda en 11 de abril de $1504^{11}$.

8. ANES ÁlVAREZ de CASTRILlón, G.: Los señorios asturianos... Este mismo autor vuelve a tratar el tema del señorío en el capítulo «Tensiones y luchas antiseñoriales en la Asturias del Antiguo Régimen» de su Economía y sociedad en la Asturias del Antiguo Régimen, Barcelona, 1988.

9. FAYA Díaz, M". A.: Los señorios eclesiásticos en la Asturias del siglo XVI, Oviedo, 1992.

10. A.R.I.D.E.A., Casa de Miranda: caja 2, doc. 2: memoria de vínculos viejos, c. 1550.

11. El mayorazgo de 1504 legitimó la vinculación de una serie de posesiones establecida por sus padres (Martín Vázquez de Quirós y doña Inés de Miranda) en las últimas décadas del siglo XV, en donde se incluían las propiedades que poseían en el valle tevergano de Valdesampedro. Por su parte, la fundación de 1504 supuso la incorporación de varias jurisdicciones: Villanueva y Coalla en el concejo de Grado y el concejo de Valdecarzana, en Teverga, que a su vez llevaba pareja la presentación de la abadía de San Pedro, cuyo titular llevaba pareja el título de Dignidad del cabildo catedralicio de Oviedo. 
Lope y Urraca realizaron una nueva agregación al mayorazgo ya existente, incluyendo, además de los bienes dotales, la herencia que Urraca de Ron recibió de sus padres.

A partir de los descendientes de éstos últimos, las incorporaciones al mayorazgo se hicieron a través de mandas testamentarias de mejora de tercio y quinto de los bienes libres habidos del testador. Asimismo, el prestigio adquirido por el linaje a lo largo de la primera mitad de la centuria, como uno de los más destacados de la región, junto con los Quirós ${ }^{12}$, son lo suficientemente acreditativos como para seguir una ventajosa política matrimonial. En este sentido, el primogénito de Lope de Miranda y Urraca de Ron, Sancho de Miranda († c. 1550), casó con una destacada dama de la nobleza avilesina, doña Leonor de las Alas ${ }^{13}$.

El prestigio del linaje debió de estar consolidado mediada la decimosexta centuria pues el heredero de los anteriores, Diego de Miranda $(\dagger 1599)^{14}$, casó con doña Inés Velázquez de Salas $(\dagger 1588)^{15}$, una sobrina del destacado prelado del reinado de Felipe II, don Fernando de Valdés Salas, Arzobispo de Sevilla, Inquisidor General y Canciller. El heredero de éstos, Lope de Miranda $(\dagger 1626)^{16}$, volvió a casar con un destacado miembro de la nobleza de la villa de Avilés, con doña Leonor Ponce de León o de Cienfuegos $(\uparrow 1599)^{17}$, cuyo apellido fue anexionado al de Miranda por el resto de los sucesores hasta que la Casa afemina en 1810 con la muerte del V marqués de Valdecarzana. El casamiento con doña Leonor supuso la incorporación de un importante patrimonio heredado de su padre Gutierre González de Cienfuegos, descendiente

(A.R.I.D.E.A., Casa de Miranda: caja 2, doc. 2; DíAz ÁlvareZ, J.: «Aproximación al patrimonio económico...», p. 94)

12. Los Quirós y los Miranda fueron los dos linajes asturianos más importantes de la región, que ascienden a la sombra de los Quiñones a lo largo de la Baja Edad Media, sustituyéndolos y conformándose como dos grupos de poder pujante en el Principado (a pesar de los lazos familiares contraídos), sirviéndose de otras familias menores que apoyaban uno y otro bando. Ampliamente emparentados entre si, configuraron unas zonas específicas de influencia, tanto en un nivel económico, como en el político, en la Asturias de la época, que se consolidó y perpetuó a lo largo de la Edad Moderna. [ $\mathrm{Vid}$. URíA Riú, J.: «Rasgo histórico-genealógico de la Casa de Valdecarzana. Siglos XIV y XV», en Revista de la Universidad de Oviedo, II, 1940, pp. 149-153 (existe una reedición en URí RIU, J.: Estudios sobre la Baja Edad Media Asturiana (Asturias en los siglos XIII al XVI), Oviedo, 1979, pp. 189-209); DíAZ Álvarez, J.: «Aproximación al patrimonio económico.... p. 88]

13. A.R.I.D.E.A., Casa de Miranda: caja 2, doc. 3: Fundaciones: memoria de vínculos viejos, c. 1550. Sobre el prestigio de las familias con las que enlazó la Casa de Miranda a lo largo del siglo XVI vid. CUARTAS Rivero, M.: Oviedo y el Principado de Asturias al final de la Edad Media, Oviedo, 1983.

14. A.R.I.D.E.A., Casa de Miranda: caja de testamentos, doc. 3: Testamento de Diego Fernández de Miranda, dado en 22 de julio de 1599 ante Juan Arias.

15. A.R.I.D.E.A., Casa de Miranda: caja de testamentos, doc. 1: Testamento de doña Inés Velázquez de Salas, dado en Grado a 21 de noviembre de 1588, ante Álvaro González del Prado.

16. A.R.I.D.E.A., Casa de Miranda: caja de testamentos, doc. 4: Testamento de Lope de Miranda, dado en San Martín de Valdecarzana a 17 de octubre de 1626 ante Pedro Arias.

17. A.R.I.D.E.A., Casa de Miranda: caja de testamentos, doc. 2: Testamento de doña Leonor Ponce de León, dado en Grado a 31 de octubre de 1599 ante Fabián de Canedo. 
de Rodrigo de la Rúa ${ }^{18}$. Ambos habían prestado servicios, de tipo administrativo, a la Corona, lo que les permitió la adquisición de un importante patrimonio.

A partir del siglo XVII, se tendió a establecer uniones de tipo exogámico, preferentemente con la nobleza ástur-gallega, lo que redundó en dar un mayor lustre al linaje ${ }^{19}$. Más aún, a diferencia de la centuria anterior, en la que los enlaces se hicieron con destacados integrantes de la nobleza regional bien dotadas pero apartadas de la línea de sucesión, lo que les impidió establecer politicas de anexión de mayorazgos. En el nuevo siglo se tendió a enlazar con damas que en un alto grado de probabilidades heredarían los mayorazgo de sus progenitores, pudiendo, la Casa de Miranda, anexionarlos. En este sentido se intentó enlazar con familias de prestigio, pues ya poseían hábitos de caballería y estaban al servido a la corona, sobre todo en el ámbito militar. Ello les permitió acceder a ciertos puestos importantes en la milicia a lo largo del siglo, mantener una serie de relaciones con personajes asentados en la corte, posibilitándoles introducirse en Madrid poco a poco a partir de la segunda mitad de la centuria, enlazando con la nobleza titulada castellana, e incorporando sus mayorazgos y títulos.

En un primer intento de unión con a la nobleza extrarregional, don Diego de Miranda, señor de la Casa de Miranda y caballero de Santiago ( $† 1632)^{20}$, casó con doña Juana de Pardo y Osorio, miembro de la nobleza ástur-gallega, perteneciente a la Casa de Lanzós. El primogénito de éstos, don Sancho de Miranda, I vizconde del Infantazgo y I marqués de Valdecarzana casó en segundas nupcias ${ }^{21}$, con su prima doña Rosenda de Pardo y Aguilar, matrimonio que tuvo como finalidad la anexión de la Casa de Lanzós, por lo que no se dudó en pleitear con otros allegados que también lo pretendian. Así, en los albores del siglo XVIII consiguen su pretensión pues en un documento de 1708 el III marqués de Valdecarzana se intitula «señor de las casas de Miranda y de Lanzós y del coto de Turón» ${ }^{22}$.

18. Vid. URÍA Riu, J.: Notas para la historia de Oviedo. El contador Rodrigo de la Rúa. Oviedo, 1969 (sin paginar); DíAZ ÁlVAREZ, J.: «Aproximación al patrimonio económico...», pp. 88 y s.

19. Esta política matrimonial fue llevada a cabo por otros linajes asturianos, así hemos de citar a los Queipo de Llano, condes de Toreno; los Vigil de Quiñones, marqueses de Santa Cruz de Marcenado; los NaviaOsorio, que heredan el título anterior por enlace matrimonial en las postrimerías del siglo XVII; los Bernardo de Quirós, marqueses de Camposagrado o los Navia-Arango, marqueses de Ferrera [Vid. Miguel ViglL, J. de D.: Historia genealógica de la Casa de Navia, Madrid, 1961 (original manuscrito, Oviedo, 1832); MADRID Álvarez, V. de la: El palacio del marqués de Ferrera, Gijón, 2003; Díaz Álvarez, J.: Ascenso de una Casa asturiana: los Vigil de Quiñones, marqueses de Santa Cruz de Marcenado, Trabajo de Investigación, inédito, Universidad de Oviedo, 2003, pp. 61 y s. y La residencia nobiliaria en la Asturias de la Edad Moderna: el caso de la familia Miranda-Valdecarzana, Memoria de Licenciatura, inédita, Universidad de Oviedo, 2004, pp. 102 y s.]

20. A.R.I.D.E.A., Casa de Miranda: caja de testamentos, doc. 5: Testamento de don Diego de Miranda, dado en Grado a 19 de junio de 1632 ante Pedro de Cañedo.

21. En primeras nupcias contrajo matrimonio con doña Juana de Estrada Idiáquez, hija de los condes de la Vega de Sella, perteneciente a la nobleza del oriente asturiano. No hubo descendencia que sobreviviera de este matrimonio. (DíAZ ÁlvareZ, J.: La residencia nobiliaria..., p. 103, nota 50).

22. A.H.A., Protocolos de Oviedo: caja 7.590: Escritura de empeño, dada en Oviedo a 26 de mayo de 1708 ante Tomás Pérez del Busto, fol. $116 \mathrm{r}$. 
Fue a partir de la segunda mitad del siglo XVII cuando se observó una clara intención de promocionar el linaje dentro del ámbito cortesano ${ }^{23}$. Don Lope Fernández de Miranda Ponce de León obtuvo, además del hábito de Santiago, el oficio palatino de Mayordomo de la Reina doña Mariana de Austria ${ }^{24}$. Ello le posibilitó enlazar con doña Josefa Trelles Simó Carrillo de Albornoz, marquesa de Bonanaro y condesa de Torralba $(\uparrow 1713)^{25}$ uniendo en su primogénito los títulos y mayorazgos de esta dama que se localizaban en Córcega y Roma ${ }^{26}$. Esta misma estrategia de anexión de títulos y mayorazgos la siguió el heredero de éstos, don Sancho Fernández de Miranda Ponce de León, III marqués de Valdecarzana, que casó con doña María de Atocha Saavedra Ladrón de Guevara Avendaño y Alvarado, condesa de Tahalú, de Escalante, de Villamor y de Mayalde, cuyo patrimonio se extendía por las provincias de Cantabria, Vizcaya, Guipúzcoa y Valencia y en la isla de Córcega27.

Llegados a este punto los marqueses de Valdecarzana dejaron de ser un simple linaje nobiliario más del Principado de Asturias. Fueron considerados ya parte de la alta nobleza castellana, desarrollando una intensa vida palatina, si bien ello no disminuyó su interés por su región de origen, pues hasta la muerte del III marqués, don Sancho, las relaciones del aristócrata con su tierra se dejan sentir, incluso en el ámbito político, participando de forma esporádica en la Junta General o en el Ayuntamiento de Oviedo, desempeñando en él su oficio de regidor. Los vínculos con su región se vieron en el interés mostrado por mantener habitables o incluso reformar sus residencias, en especial su palacio de Grado junto al que mandó construir una suntuosa capilla privada; además mandó construir en Oviedo una villa suburbana de recreo al estilo de las que había en la corte ${ }^{28}$. A pesar de todo, los intereses que mantuvieron en Madrid les empujaron a sacrificar su poder político en la Junta, al menos de forma directa, pues perdieron paulatinamente, desde el último cuarto del siglo XVII, votos como diputados en la Junta General.

23. El linaje comenzó a instalarse de forma temporal en la corte al menos desde el año 1653 en que tenemos noticia del alquiler de una casa por parte del I marqués de Valdecarzana al canónigo don Pedro Fernández del Campo, en la calle del Pez, frente a San Plácido, por el precio de 2.500 reales anuales (A.R.I.D.E.A., Casa de Miranda: caja 18: Escritura de arrendamiento dada en Madrid en noviembre de 1653).

24. A.R.I.D.E.A., Casa de Miranda: caja de testamentos, doc. 8: Testamento de don Lope de Miranda Ponce de León, dado en Oviedo a 19 de agosto de 1683 ante Diego Rato Hevia.

25. Esta aristócrata era de ascendencia asturiana. (Vid. Trelles Villademoros, J. M.: Compendio genealógico histórico de la ascendencia de don Manuel Joachin de Cañas Acuña Silva Castilla, Luarca, 1755, ff. $16 \mathrm{r}-17 \mathrm{v}$.)

26. A.R.I.D.E.A., Casa de Miranda: caja de testamentos, doc. 9: Testamento de doña Josefa de Trelles Simó Carrillo de Albornoz, dado en Oviedo a 17 de febrero de 1713 ante Domingo Blanco Sacedo.

27. A.H.A., Protocolos de Oviedo, Caja 7.960: Carta de poder del marqués de Valdecarzana, dada en Oviedo a 3 de junio de 1712 ante Diego Blanco Sacedo. A.R.I.D.E.A., Casa de Miranda: caja 2, doc. 8: Toma de posesión de don Judas Tadeo Fernández de Miranda, dado en Madrid a 17 de noviembre de 1757 ante José de Casas.

28. Vid. Diaz Álvarez, J.: La residencia nobiliaria..., pp. 169-185. 
A partir del siglo XVIII los marqueses de Valdecarzana se establecieron de forma definitiva en la Corte. El éxito de estas estrategias de consolidación del linaje en la misma se vio correspondido en las dos generaciones posteriores, cuando llevaron a cabo matrimonios con la alta nobleza castellana, llegando a enlazar con la Grandeza de España. Ello tuvo lugar cuando el IV marqués, don Sancho $(\dagger 1757)$, casó con doña Ana Catalina de Villacis Manrique de Lara y Fernández de Córdoba, condesa de las Amayuelas, de Taracena y de Peñaflor, vizcondesa de Centenera y baronesa de diversas baronías en Cataluña; cuyo patrimonio se extendía por las provincias de Valladolid, Salamanca y Cataluña y aglutinaba diversos mayorazgos y títulos nobiliarios, incluida la Grandeza de España, que recaía sobre el condado de las Amayuelas ${ }^{29}$.

La vida de los Valdecarzana se tornó totalmente cortesana y como tales se comportaron como el resto de la nobleza absentista, sus patrimonios fueron administrados por diversos mayordomos ${ }^{30}$ y las posesiones asturianas no sobresalían en ningún sentido sobre el resto repartidas por toda la Península. En este sentido, a partir del III marqués los titulares de Valdecarzana no tuvieron en consideración la abadía tevergana de San Pedro como panteón familiar, que había cumplido esta función de forma ininterrumpida desde la primera mitad del siglo XVI.

La posición social del IV marqués posibilitó casar a su descendencia con destacados miembros de la corte de Carlos III. Sus hijas, doña María Antonia, doña Francisca Javiera, doña María del Pilar y doña María Cayetana, casaron con don José Antonio de Rojas, conde Mora y marqués de la Torre; don Pedro de Luján y Góngora, marqués de Almodóvar del Río ${ }^{3 !}$ y de Ontiveros, conde de Canalejas, Adelantado de la Florida, Caballero del Toisón de Oro ${ }^{32}$; el duque de Arenberg y el marqués de Escalona, respectivamente $^{33}$.

El hermano de aquellas y heredero de los títulos anexionados por la Casa de Miranda a lo largo de siglo y medio, don Judas Tadeo $(† 1810)$, enlazó con un miembro de la alta nobleza italiana instalada en la corte española, doña Isabel Reggio Branciforte y Gravina, heredera de los diversos títulos de sus padres: don Esteban Reggio Branciforte Saladino y Colona, príncipe de Yachi, y doña Giovanna Raimonda

29. A.R.I.D.E.A., Casa de Miranda: caja de testamentos, doc. 12: Testamento de doña Ana Catalina Villacis Manrique de Lara y La Cueva, dado en Madrid a 6 de noviembre de 1765, ante don Domingo José de Casas.

30. A.H.N., Sección Nobleza: Cifuentes, caja 9, docs. 15-20.

31. El título tue elevado a la categoría de ducado en 1780 por gracia de Carlos III (MARQUEZ DE LA PLATA, V. M", VAlERO DE BERNABÉ, L.: El libro de oro de los duques, Madrid, 1994, pp. 47 y s.)

32. Este noble era descendiente, por vía materna, del Adelantado y conquistador de la Florida don Pedro Menéndez de Avilés, perteneciente a la nobleza asturiana. (Vid. Miguel Vigil, C.: Noticias biográficogenealógicas de Pedro Menéndez de Avilés primer adelantado y conquistador de la Florida. Avilés, 1892; Soljs de Merás, G.: Pedro Menéndez de Avilés y la conquista de la Florida, edición de J. M. Gómez-Tabanera, Oviedo, 1990 , pp. 245 y ss.)

33. A.R.I.D.E.A., Casa de Miranda: caja de testamentos, docs. 11: Testamento de don Sancho de Miranda, dado en Madrid a 18 de noviembre de 1757 ante don Domingo José de Casas, y 12. 
Chartres $^{34}$. Este personaje encarnó el éxito todas las políticas matrimoniales llevadas a cabo desde hacía más de siglo y medio. Sobre su persona concentró una docena de títulos nobiliarios, una Grandeza de España, diversos mayorazgos ${ }^{35}$, oficios palatinos ${ }^{36}$, una posición envidiable en la corte ${ }^{37} \mathrm{y}$ un extenso patrimonio económico dispersado por diversas provincias españolas.

\section{EVOLUCIÓN DEL PATRIMONIO ECONÓMICO}

El patrimonio económico que la Casa de Miranda fue acumulando a lo largo de los siglos XVI y XVII se extendió principalmente por los actuales concejos de Avilés, Gozón, Soto del Barco, Castrillón, Illas, Pravia, Grado, Salas, Belmonte de Miranda, Somiedo, Teverga, Tineo, Allande y Quirós; y se complementó con propiedades en la vertiente leonesa en las Babias. Estas propiedades fueron incrementadas con otras localizadas en los concejos de Oviedo, Llanera, Las Regueras, Proaza y Yernes y Tameza ${ }^{38}$ (vid. Mapa 1).

En la Asturias del Antiguo Régimen el principal medio de riqueza de la nobleza fue la tierra, generalmente cedida en renta. Con la finalidad de consolidar los patrimonios económicos nobiliarios, la nobleza se acogió a su derecho de crear mayorazgos $^{39}$, verdadera institución de carácter social y económica característica del Antiguo Régimen. A través del mayorazgo los bienes patrimoniales fueron transmitidos por vía

34. Díz Álvarez, J.: La residencia nobiliaria..., pp. 104 y s.

35. A.H.N., Sección Nobleza: Bornos, caja 456, doc. 7; Cifuentes, caja 4, docs. 4 y 12, caja 5, docs. 1, 4, 6, 8, 9 y 13; Fernán Núñez, caja 1.215, doc. 28.; Osuna, caja 1.373, docs. 11 y 12. A.H.N., Consejos 9.894, año 1757 , exp. 3 .

36. A.H.N., Sección Nobleza, Osuna, carpeta 305, docs. 2 y 2 bis; carpeta 306, doc. 13.

37. Don Judas Tadeo Fernández de Miranda Ponce de León Villacis Manrique de Lara y la Curva Ladrón de Guevara Avendaño y Gamboa González de Cienfuegos Pardo de Lanzos Carrillo y Albornoz, V marqués de Valdecarzna, de Bonanaro, de Taracena y de Rucandio, Conde de Tahalú, de Escalante, de las Amayuelas, de Peñaflor, de Torralba, de Mayalde y de Villamor, Grande de España y Gentilhombre de Cámara de S. M. con Ejercicio, Caballero Gran Cruz de la Distinguida orden de caballería de Carlos III, fue nombrado Sumiller de Corps y asistió a la coronación del emperador de Austria en representación de la corona española en 1792 en Viena. Falleció en la casa-palacio de las Conchas de Salamanca en 27 de septiembre de 1810. No tuvo descendencia, por lo que le heredó su sobrina doña Lucía de Rojas Fernández de Miranda, condesa de Mora. (A.R.I.D.E.A., Casa de Miranda, Caja 2, doc. 11: Toma de posesión de doña Lucía de Rojas y Fernández de Miranda, ante Miguel José García de la Madrid. A.H.N., Estado 3.436/2, n ${ }^{\circ}$ 1, año 1783; Estado, libro 1.042, fol. 25 r.)

38. Esta localización la hemos realizado a través de un extracto de rentas percibidas por la Casa de Miranda en la década de 1640. Documento que se adjuntó a un memorial por el titular de la Casa en la época, don Sancho Fernández de Miranda y Ponce de León, I vizconde de Villanueva del Infantazgo y caballero de Santiago, solicitando un título de Castilla de conde o marqués. (A.R.I.D.E.A., Casa de Miranda, caja de arrendamientos, $\mathrm{s} / \mathrm{c}$ ).

39. A esta institución se acercó de forma modélica, haciendo referencia a su faceta más jurídica, Clavero, B.: Mayorazgo. Propiedad fendal en Castilla (1369-1836), Madrid, 1974. El aspecto económico lo abordó posteriormente PÉrez PICAZO, M`. T.: El mayorazgo en la historia económica de la Región de Murcia, Madrid, 1990. 
hereditaria al primogénito y estuvieron sujetos a prohibición de enajenación y venta -para lo que se requería Licencia Real- permaneciendo en la familia a perpetuidad. En este sentido, el mayorazgo no supuso la congelación de una serie de bienes transmisibles por vía de primogenitura; desde su fundación fue un órgano económico vivo que creció con el paso de las generaciones a través del sistema hereditario de la incorporación de la mejora de tercio y remanente del quinto, que se obtenía sobre los bienes libres habidos de la generación anterior.

El patrimonio de los Miranda se originó a partir de la fundación del mayorazgo en 1504 por Diego de Miranda. El grueso de los bienes amayorazgados estaba englobado en una serie de vínculos que se perpetuaron dentro de la familia a lo largo del siglo XV debido a Martín Vázquez de Quirós y su esposa, Inés de Miranda. En esta fundación ya se había incluido la herencia que el fundador recibió de sus progenitores y que se concentraba principalmente en valle de Valdesampedro, concejo de Teverga, de donde procedía el linaje. El fundador incrementó lo recibido de sus padres con la agregación de los cotos de Villanueva y Coalla (Grado), el concejo de Valdecarzana (Teverga), que además incluía la presentación de la abadía de San Pedro, llevando pareja una Dignidad dentro del cabildo catedralicio ovetense. El sucesor de Diego, Lope de Miranda, añadió, junto con su esposa doña Urraca de Ron, los cotos de Luerces, Quinzanas, Soto de los Infantes, la hacienda de Felgueras, diversos bienes en el concejo de Somiedo adquiridos a través de compraventa, las rentas de Coañana y de Majua en este mismo concejo, así como los vasallos que doña Urraca heredó de sus padres ${ }^{40}$, junto con las rentas y molinos de Cobillos y diversas presentaciones eclesiásticas ${ }^{41}$. Una de las últimas agregaciones importantes del mayorazgo tuvo lugar en las postrimerías de la primera mitad del siglo XVI a partir de los bienes que doña Leonor de las Alas incorporó como dote al casarse con Sancho Fernández de Miranda ${ }^{42}$, lo que supuso un patrimonio valorado en 2.823 ducados $^{43}$. A partir de los sucesores de Sancho y doña Leonor las incorporaciones hechas fueron a través de disposiciones testamentarias de mejora de tercio y quinto.

Los bienes raíces de la Casa de Miranda se comenzaron a configurar a partir de su concejo de origen, así como en los concejos en los que tuvieron una mayor presencia: Grado y Salas. En todo caso, reforzaron su patrimonio alrededor de sus principales jurisdicciones: Valdecarzana, en Teverga; Villanueva, en Grado y Soto de los Infantes, en Salas. De hecho, según el catastro de Ensenada, en estos lugares fueron conside-

40. Se refiere al coto de Sena en el concejo de Ibias, que en la segunda mitad del siglo XVI cambia de titularidad.

41. A.R.I.D.E.A., Casa de Miranda: caja 2, doc. 2.

42. La agregación de doña Leonor de las Alas fue valorada en 1.175 .757 maravedíes, distribuidos de la siguiente forma: 625.757 maravedíes en concepto de dote matrimonial, herencia y mejora de tercio materna: 400.000 maravedíes y herencia paterna: 150.000 maravedíes (A.R.I.D.E.A., Casa de Miranda: caja 2, doc. 3).

43. A.R.I.D.E.A., Casa de Miranda: caja 2, doc. 3-a: Bienes habidos de Sancho de Miranda y doña Leonor de las Alas, c. 1550. 
rados los mayores hacendados, contabilizando un patrimonio rústico en 9.880 días de bueyes, 21 casas, 14 hórreos y 5 molinos, que rentaban al año 11.760 ducados $^{44}$.

Por otro lado, dada la necesidad de la nobleza de incrementar su nivel de rentas se vio abocada a aforar parte de las tierras dependientes de la Iglesia ${ }^{45}$. Los Miranda fueron foreros de diversos monasterios. La documentación utilizada no nos da información sobre las comunidades monásticas concretas, pero si las órdenes a las que pertenecían: benitos y bernardos. En este sentido sabemos que en la década de 1640 el I marqués de Valdecarzana, satisfacía la cantidad de 500 reales en concepto de aforamientos ${ }^{46}$.

$\mathrm{Si}$ bien es cierto que la mayor parte de los patrimonios nobiliarios estuvieron configurados por bienes raíces, no menos cierto fue el aprovechamiento de otras fuentes de ingresos. El ganado se presentó como un negocio nada despreciable, por lo general se cedió en comuña o en aparcería, lo que suponía el aprovechamiento agrario campesino con mínimos costes y grandes beneficios ${ }^{47}$; del mismo modo que hubo parte de ganado gestionado directamente por sus propietarios. La Casa de Miranda no fue ajena a los pingues beneficios que podía extraer de la cesión del ganado vacuno en pequeños lotes. En 1569 se documenta para este linaje una cabaña ganadera de 1.500 cabezas $^{48}$, en 1626 Lope de Miranda declara en su testamento ganado por valor de 1.500 ducados $^{49}$ y en la averiguación que desde el consejo de Hacienda se hizo a Diego de Miranda en 1592 los testigos dijeron de él era «hombre rico y poderoso, entre los mas del Principado, que vendía, cada año, mil vacas y bueyes, y muchos carneros, y mas de mil quintales de hierro, de una herrería que tenía $)^{50}$.

Los oficios municipales constituyeron otro de los capítulos de inversión de la Casa de Miranda. Una vez asentado su poder señorial en el centro regional como se

44. FAYA DÍAZ, M. a A.: «La propiedad nobiliaria...», 118.

45. Esta tendencia - tan corriente entre la vecina nobleza gallega- aún está por determinar para el caso asturiano. Resulta clásica la teoría de que la nobleza media gallega prosperó como forera de los monasterios y de la alta aristocracia absentista gallega. Así, podemos citar los casos de linajes como los Castro, los Sotomayor, los Ulloa, los Monterrey, etcétera, quienes a su vez cedieron las tierras aforadas en subarrendamientos. Sobre este aspecto resultan interesantes las aportaciones de BARREIRO MALLÓN, B.: La jurisdicción de Xallas en el siglo XVIII. Población, sociedad y economía, Santiago de Compostela, 1973; GARCIA LOMBARDERO, J.: La agricultura y el estancamiento económico de Galicia en la España del Antiguo Régimen, Madrid, 1973; VILLARES, R.: La propiedad de la tierra en Galicia, 1500-1936, Madrid, 1986; BAZ VICENTE, M. ${ }^{a}$ J.: Señorio y propiedad foral...

46. A.R.I.D.E.A., Casa de Miranda: caja de arrendamientos (s/c): Memoria de las rentas del I marqués, $c$. 1645.

47. BARREIRO MALLÓN, B.: «La introducción de nuevos cultivos y la evolución de la ganadería en Asturias durante la Edad Moderna», en Actas del Congreso de Historia Rural. Siglos XV-XIX, Madrid, 1984, pp. 287-319; GARCiA FERnÁNDEZ, J.: Sociedad y organización tradicional del espacio en Asturias, Gijón, 1989 , pp. $45-52$

48. A.R.I.D.E.A., Casa de Miranda, caja de apeos de bienes (s/c). Datos semejantes para fechas posteriores los aportan CuArtas Rivero, M.: Oviedo y el Principado de Asturias a finales de la Edad Media, Oviedo, 1983, p. 103.

49. A.R.I.D.E.A., Casa de Miranda: caja de testamentos, doc. 4.

50. GonZÁlez-Fierro OrdóÑez, F.: Apunte geográfico e histórico..., pp. 32 y. 
ve en el Mapa 1, se intentó adquirir una serie de alferazgos, regidurías, escribanías, alguacilías, etcétera, en aquellos concejos en los que tenían un mayor poder económico en el periodo cronológico 1558-1643. La obtención de estos oficios significó la acotación de poder dentro de los municipios de realengo a través del ejercicio de la política municipal, que si bien no fueron ejercidos de forma directa por sus poseedores, se delegaban en segundas personas afines al linaje poseedor. Así, el eje político marcado por los Miranda atravesó la región de norte a sur desde la costa central asturiana a la montaña occidente ${ }^{51}$, incluso traspasando los límites asturianos al tener importantes intereses en las Babias. Las inversiones económicas fueron considerables pues en el periodo $1558-1643$ se realiza un gasto que supera los 100.000 reales de vellón como podemos ver en el Cuadro $\mathrm{I}^{52}$.

\section{EL PATRIMONIO SEÑORIAL}

La ostentación -a veces la detentación como veremos en nuestro caso- de la titularidad de uno o varios señoríos tuvo varias causas. En primer lugar, para la nobleza fue una forma más de afianzarse ante los grupos sociales inferiores; pero también una manera de adquirir consideración entre los individuos de su mismo grupo social. En segundo lugar, la adquisición de un señorío fue pareja con unos intereses económicos nada despreciables. En este sentido, la posesión de las jurisdicciones estuvo asociada

51. Un caso paradigmático de influencia político-económica de la Casa de Miranda lo observamos en el control que ejercieron en el concejo de Teverga. Aquí poseyeron el concejo de Valdecarzana en calidad de señorío, pero su poder se extendió a los valles de Valdesampedro y Valdesantibañez, así como a Páramo de Focella, los tres concejos redimidos e independientes. En los dos primeros concejos ejercieron el oficio de Justicias Mayores, oficio que en sí mismo fue de tipo electivo, a través de los votos del regimiento del ayuntamiento. Valiéndose de la coacción de tipo económico -dado que los Miranda eran los principales propietarios de tierras de todo el concejo tevergano- se hicieron con el control del oficio, del que obtenían una renta anual nada desdeñable. Según una valoración de las rentas del marquesado de Valdecarzana de finales de la primera mitad del siglo XVII obtenían en tanto y cuanto Justicias Mayores de los mencionados valles: 280 fanegas de trigo, valoradas en 5.040 reales, y 240 cántaras de vino, valoradas en 1.680 reales. A ello se unió el derecho de presentación de la abadía y el beneficio curado de Santo Tomás de Riello. Algo semejante lo vemos en Páramo de Focella, antiguo señorío eclesiástico que se redimió en el proceso de enajenación de los bienes eclesiásticos llevada a cabo por Felipe II. Los vecinos del concejo se hallaban libres de contribución por un privilegio real, a pesar de ello, debieron de satisfacer un canon anual de 66 reales al señor que fuera de la Casa de Miranda en tanto y cuanto era el comendero. Este pago representó, de hecho, un pago jurisdiccional, pero encubierto bajo la encomienda. En este sentido hemos de recordar la apropiación indebida de no pocas encomiendas eclesiásticas durante la Baja Edad Media, perpetuándolas y cambiando su titularidad por la de coto. (A.R.I.D.E.A., Casa de Miranda: caja de arriendos: Rentas de don Sancho Fernández de Miranda, I marqués de Valdecarzana, c. 1645.)

52. La casa de Miranda fue poseedora c. 1645 de los alferazgos mayores de los concejos de Avilés, Grado y Somiedo, en Asturias, y de las Babias (de Suso y de Yuso), en León; de regimientos en los municipios asturianos de Avilés, Belmonte de Miranda, Castrillón, Gijón, Illas, Oviedo, Pravia, Salas y Somiedo y en Babia de Suso en León; de escribanías en Grado y Pravia, amén de otros (tales como Depositarías o Procuramientos) localizados en los concejos ya citados. (A.R.I.D.E.A., Casa de Miranda: caja de arrendamientos: Ibidem; DiAz Álvarez, J.: «Aproximación al patrimonio económico...», p. 101) 
a la coacción extraeconómica, llegando, incluso, a la usurpación de estos espacios de poder a sus legítimos dueños ${ }^{53}$.

\section{I Los señorios: identificación, localización, evolución histórica}

Con anterioridad comentamos cómo el proceso de enajenación de los señoríos eclesiásticos fomentó el incremento del señorío laico, pero también la posibilidad de redención de ciertos lugares de sus antiguos señores. El señorío se transformó en un bien más transmisible, susceptible de compraventa.

Además en no pocas ocasiones, muchos de los señoríos que conocemos configurados como tales a lo largo de la Edad Moderna comenzaron siendo malaterías u hospitales de peregrinos, hundiendo su origen en la Edad Media, dependientes de la autoridad eclesiástica, principalmente la episcopal, que ante la imposibilidad de gestionar sus bienes de forma directa las entregaron a laicos para su control. Esta administración solió continuarse de padres a hijos, llegando a cuestionar la titularidad de la encomienda a su legítimo poseedor, desposeyéndolo de él ${ }^{54}$, valiéndose de la extorsión y la violencia y tornando la propiedad en coto privado ${ }^{55}$.

La jurisdicción más destacada de la Casa de Miranda fue la del concejo de Valdecarzana, uno de los tres valles del concejo de Teverga, del que procedía este linaje y que dio nombre al marquesado que recibió la familia. Esta jurisdicción fue donada a los Quirós en 1372 «con su termyno y con los fueros y derechos de dicho conçexo y con la presentazion de la yglesia de San Pedro e las mas apresentaziones que perteneçen a los dichos lugares». A través de diversos enlaces matrimoniales de tipo endogámico, dado que los Miranda y los Quirós procedían de un mismo tronco, la propie-

53. A lo largo de la Edad Media y Moderna la nobleza aforó tierras de la Iglesia para poder incrementar sus ingresos económicos. Las condiciones del contrato eran ventajosas para la aristocracia pues el contrato, por lo general de largo plazo -foro por espacio de tres vidas-, estipulaba un pago anual muy bajo, a su vez el forero subarrendaba estas propiedades a través de contratos de corto plazo obteniendo un mayor beneficio. En otras ocasiones la Iglesia acudió a la nobleza para hacerla comendera y administradora de ciertos establecimientos eclesiásticos (cotos, malaterías, hospitales de peregrinación, etcétera), perpetuándose este oficio en determinadas familias varias generaciones. Ello llevó a no pocos nobles -a la par de ir inmiscuyéndose en asuntos que no eran de su competencia-a negarse a entregar estas propiedades a sus legítimos poseedores, amparándose en su oficio, quedándose con estos espacios a perpetuidad. (FAYA DiAZ, M." A.: Los señoríos eclesiásticos..., pp. 242 y ss.)

54. Así en 1490 se pide al corregidor del Principado desde la corte que mande guardar la ley que en 1390 dio Juan I, confirmando las dadas en Alcalá de Henares por Alfonso XI, referente a la prohibición de entregar encomiendas de los monasterios; petición que habja sido solicitada con anterioridad por don Juan Arias, obispo de Oviedo, para prevenir las pretensiones de Diego de Miranda sobre las encomiendas del monasterio de Cornellana (A.G.S., R.G.S., 149004, 148)

55. Vid. TOlivar Faes, J. R.: Hospitales de leprosos en Asturias en las edades Media y Moderna, Oviedo, 1966. FAYA DiAz, M. A.: Los señorios eclesiásticos... y «Los señoríos asturianos en tiempo de Felipe II», en BIDEA, 158, 2001, pp. 109-121. 
dad quedó en manos de los Miranda definitivamente en las postrimerías del siglo XV ${ }^{56}$. Las entidades de población de Taja y Urría se mantuvieron bajo el yugo jurisdiccional de los Miranda, a pesar de estar enclavadas en el valle de Valdesantibáñez (Teverga), concejo de obispalía que fue redimido por los mismos vecinos; fueron incorporadas por la fuerza a la jurisdicción de Valdecarzana ${ }^{57}$.

Este mismo proceso de usurpación lo vemos en la apropiación forzosa de la jurisdicción de la malatería de La Cabruñana, de la que esta familia era comendera desde la Baja Edad Media. Lo mismo puede decirse de Coalla en donde desde los albores del siglo XVI los Miranda se interpusieron y arbitraron a su favor a través del nombramiento de la justicia. Este proceso de usurpación a través de mañas belicosas se continuó a lo largo de la centuria por los sucesores de aquél, hasta hacer de él coto solariego. Con esta nueva situación se demandó a los vecinos el quiñón (1/5) de lo cultivado y la mitad de la recolección de los árboles, así como la imposición de un yantar que se cobraba en numerario ( 62 maravedíes por vasallo). Un proceso semejante lo sufrieron los cotos de Villanueva y La Mata en el mismo concejo de Grado ${ }^{58}$.

Usurpación como las anteriores también se dio en el coto de Soto de los Infantes (Salas), donde los Miranda impusieron el nombramiento de justicia, llegando a hacer solariego el lugar de Silvota. Ello dio lugar a un pleito entre Diego de Miranda y Juan de Tineo, éste representó a los vecinos del coto, a mediados del siglo XVI ${ }^{59}$. El pleito debió de haber fallado a favor de los Miranda pues desde entonces fue considerado uno de sus puntos fuertes, incluso fue el motivo que dio lugar a la denominación del vizcondado concedido c. 1639.

Los cotos de Muros, Ranón y La Arena pasaron a los Miranda a través de vía matrimonial. Fueron incorporados en la segunda mitad del siglo XVI por doña Leonor Ponce de León -o de Cienfuegos- († 1599), que los hubo heredado de su padre Gutierre Gonźález de Cienfuegos. El coto de Muros fue adquirido por Rodrigo de la Rúa, contino de Carlos V, en 1515 a los Quiñones ${ }^{60}$. A la muerte de éste, le heredó su primogénito, Gutierre, que recibió el mayorazgo que en su favor se fundó en $1529^{61}$, en el que se incluyeron las jurisdicciones del concejo de Allande y los cotos de Puerto (en Ribera de Abajo) y Muros (en Pravia). Los cotos de Ranón y La Arena fueron comprados por Gutierre González de Cienfuegos al monasterio de Cornellana en 1543 por la suma de

56. A.R.I.D.E.A., Casa de Miranda: caja 2, doc. 4: Compromiso sobre el coto de Soto de los Infantes a favor de Sancho de Miranda, c. 1550.

57. FAYA DÍAZ, M." A.: Los señoríos eclesiásticos..., p. 78.

58. Ibidem, pp. 68 y s.

59. Ibidem, pp. 74 y s.

60. GonzÁlez-Fierro Ordóñez, F.: Apunte geográfico e histórico de la villa de Muros de Nalón y del puerto de San Esteban de Pravia, con alguna noticia particular de la parroquia de Santa Maria de Muros, Oviedo, 1953, p. 30. URÍA Rıú, J.: Notas para la historia de Oviedo. El contador Rodrigo de la Rúa, Oviedo, 1969 (sin paginar).

61. DíAZ Álvarez, J.: «Aproximación al patrimonio económico...», p. 94. 
250 ducados de oro, junto con las presentaciones eclesiásticas que implicaban ${ }^{62}$. Con el tiempo estos cotos (Muros, Ranón y La Arena) fueron desgajados de la Casa de Cienfuegos, al ser entregados a doña Leonor Ponce de León como parte de la dote al casar con su primo Lope Fernández de Miranda, heredero de la Casa de Miranda ${ }^{63}$.

El coto de Aguino (en el concejo de Somiedo) estaba dividido en las postrimerías del siglo XV entre tres poseedores: los Tineo, los Flórez y los Miranda. Juan de Tineo había otorgado venta de su parte, recibida en herencia de su padre, a Álvaro Flórez, quedando como propietario de $2 / 3$ del mismo. A su muerte, su viuda, Urraca de Valdés, pleiteó con Sancho de Miranda por la posesión del tercio restante. Finalmente, aquélla otorgó venta de su parte a favor de los Miranda entre 1545 y 1566 incluyendo también el coto de Perlunes. Los descendientes de los Flórez-Valdés demandaron en 1610 a Lope de Miranda solicitando de la Chancillería de Valladolid las ventas otorgadas años atrás, fallándose a favor de los demandantes y obteniendo el coto de Perlunes y la mitad del de Aguino. La sentencia fue recurrida por los Miranda, no resolviéndose el conflicto hasta 1651 en que se da confirmación de la sentencia ya fallada ${ }^{64}$.

El coto de Gúa, que incluía los lugares de Caunedo y El Puerto, enclavado en el concejo de Somiedo, fue propiedad del monasterio de bernardas del mismo nombre mediado el siglo XVI. Según el catastro de Ensenada sus vecinos se habían redimido. Lo cierto es que cuando las monjas se trasladan a la villa de Avilés, los vasallos dieron poder a Baltasar Flórez para que les representaran en la corte y negociara su redención. El apoderado parece que se concertó con Sancho de Miranda para que éste comprara el coto a las religiosas, que se lo vendieron por 400 ducados, en perjuicio de los vasa$11 \mathrm{~s}^{65}$.

\subsection{Los vasallos}

El estudio del vecindario de las jurisdicciones que estaban bajo la dependencia de la Casa de Miranda resulta dificultoso. Las fuentes utilizadas para ello no son lo suficientemente esclarecedoras para los fines que nos trazamos. La población de los señoríos de los Miranda no siempre se contabilizó de forma independiente, sino que, en muchas ocasiones, fue incluida dentro de la población del concejo en el que se localizaba el coto ${ }^{66}$. Sólo contamos con datos esporádicos que nos comentan el número de vasallos habidos en un coto determinado en una fecha concreta, recuento hecho para

62. FAYA DÍAZ, M.a A.: Los señoríos eclesiásticos..., p. 71.

63. GONZÁlEZ-FIERRO ORDÓÑEZ, F.: Apunte geográfico e histórico ..., p. 30.

64. FAYA Díaz, M." A.: Los señorios eclesiásticos..., p. 77.

65. ANes Álvarez de CASTRILlón, G.: Los señorios asturianos..., p. 112; FAYA Díaz, M." A.: Los señoríos eclesiásticos..., pp. 58 y 77.

66. Esto podemos verlo en el censo de población de Castilla de finales del siglo XVI, en el que, para nuestro caso, tan sólo se tratan de forma independiente los cotos de Gúa (56 vecinos), La Cabruñana (19 vecinos), Soto de los Infantes (72 vecinos), el concejo de Valdecarzana (143 vecinos) y Matallana (100 vecinos). (Molinie Bertrand, A., Garcia España, E. (eds.): Censo de Castilla de 1591. Vecindarios, Madrid, [984, pp. 59, 62, 64 y s. y 321 ). 
alguna cuestión de tipo administrativa de las posesiones del titular. En este sentido sabemos que, a través del inventario de bienes de Rodrigo de la Rúa, c. 1530, el coto de Muros contaba con unos 40 vasallos, pues en una información sobre esta jurisdicción se la valoró en 200.000 maravedíes, tasándose en 5.000 cada vasallo ${ }^{67}$.

La propiedad señorial de la Casa de Miranda constituyó un importante conjunto territorial dentro de la región, pues ya en la segunda mitad del siglo XVII nos encontramos a las jurisdicciones de esta casa nobiliaria como un espacio territorial, si bien disgregado, susceptible de ser tenido en cuenta a la hora de hacer los repartimientos de soldados con los que el Principado había de servir a la defensa de la Monarquía Hispánica $^{68}$. En los repartimientos de soldados o de dinero a favor de la corona, los señoríos asturianos del marqués de Valdecarzana fueron incluidos en un mismo grupo geo-político que contabilizaba, en función de su población -en este caso, los vasallos- al mismo nivel que cualquiera de los diferentes concejos asturianos. ${ }^{69}$.

En la Diputación de 3 de febrero de 1663 en el repartimiento de un servicio a la Corona de 500 hombres a las «jurisdiciones de la Casa de Miranda» le correspondieron «cinco soldados y dos tercios y medio que se an de sortear con el concejo de Grado»" uno en los que esta familia nobiliaria asturiana tenía un amplio poder. Para darnos una idea del volumen de vasallos que habitaban las diferentes jurisdicciones de los Miranda cabe decir que suponía el $1 \%$ de toda la contribución, porcentaje que aportaron otros concejos asturianos como Ribadesella, Nava, Quirós, Teverga, Somiedo e Ibias ${ }^{71}$.

Para el siglo XVIII las fuentes no son del todo esclarecedoras, a pesar de ello el catastro de Campoflorido, como ya hemos visto para el siglo XVII, incluye a todos los vecinos de «las jurisdicciones de la casa de Miranda», los que suponen 139; no obstante no incluye los de los cotos Gúa (28 vecinos) y Aguino (10 vecinos) ni los vecinos del concejo de Valdecarzana; éstos últimos son englobados con el resto de los habitantes del concejo de Teverga, por lo que no podemos precisar su número ${ }^{72}$. A pesar de ello, los vecinos de los señoríos del marqués de Valdecarzana sumaron más de 177 en los primeros años del siglo XVIII. Una contabilización más aproximada nos la da el catastro de Ensenada. El censo nos aporta la vecindad de todos los cotos del marquesado excepto la de las jurisdicciones de Coalla y Villanueva (Grado), el resto suman

67. A.R.I.D.E.A., Casa de Miranda, Caja 2, doc. 5: Información sobre cotos, c. 1550.

68. Esta misma visión de los cotos del marquesado de Valdecarzana se observa en el vecindario realizado por el catastro de Campoflorido de 1712, pero con la peculiaridad de que no incluye las jurisdicciones de los cotos de Gua y Aguino [Actas de las Juntas y Diputaciones del Principado de Asturias (1652-1672), tomo VII, Oviedo, 1964, p. 119. Censo de Campoflorido, 1712. Vecindario general de España, vol. I, ed. fac., Instituto Nacional de Estadística, Madrid, 1995, pp. 402 y s.]

69. En la Junta General de 10 de marzo de 1649 se hizo repartimiento de soldados para servir al rey, a las mencionadas «Jurisdiciones de la Casa de Miranda» le correspondieron tres soldados, además de una contribución de 279 reales de vellón y 126 de plata. (Actas de las Juntas y Diputaciones..., tomo VI, pp. 221 y s.)

70. Actas de las Juntas y Diputaciones..., tomo VII, Oviedo, 1964, p. 119.

71. Ibidem, pp. 115 y ss.

72. Censo de Campoflorido, 1712. Vecindario..., pp. 402 y s. 
un total de 827 vecinos $^{73}$. De la cifra tan sólo podemos comentar el hecho del aumento de población sufrida en estas entidades de población. En este sentido podemos hablar de forma comparativa de la tendencia al aumento de la población desde las postrimerías del siglo XVI a mediados del XVIII; así, el coto de Ranón en 1712 contabilizó 10 vecinos y un siglo y medio más tarde 139; caso similar lo vemos en Muros, pues el censo de 1591 da la cifra de 60 vecinos y Ensenada 184; o en el coto de Gúa que para las mismas fechas se observan 56 y 170 vecinos respectivamente.

\subsection{Las facultades jurisdiccionales}

El ejercicio de la jurisdicción supuso el trasvase a manos privadas de unas competencias de carácter público. El señor pasó a ser la única autoridad con plenos poderes, no sólo sobre un cierto territorio, sino sobre los individuos que allí vivieran, los vasallos. La titularidad de un coto tuvo una significación política de mayor consideración. El gobierno y administración de la jurisdicción implicó un fuerte grado de parcialidad por parte del titular. El señor pudo establecer a su arbitrio las reglamentaciones que le parecieran adecuadas, gozó del derecho de nombrar los oficios -jueces, alcaldes, merinos y escribanos-, que pudiera controlar y le fueran favorable. A través de la jurisdicción civil y criminal y el bajo mero mixto imperio controló la administración de justicia, ejerciendo también el derecho de apelación. A todo lo que hubo que sumar la percepción de diferentes derechos señoriales. Esta situación llevó a que el titular de cualquier señorío estableciera situaciones abusivas como pudo ser el mantener el control sobre los recursos y actividades económicas, sacando de ello el mayor provecho, favorecido por su posición social; lo que, por otro lado, llevó a no pocos conflictos y tensiones sociales.

En no pocas ocasiones, la nobleza se alzó con el derecho de administrar justicia en otros espacios no señoriales, así como en espacios de realengo que eran entregados por un periodo a la nobleza local para que la administraran en su lugar en categoría de comenderos, principalmente en castillos reales. Son escasas las fuentes que nos hablan del gobierno directo de las jurisdicciones de la Casa de Miranda, principalmente se hacía a través de la justicia impuesta. No obstante, en ocasiones el señor impuso una serie de normas de gobierno a través del establecimiento de ordenanzas ${ }^{74}$.

73. El reparto del vecindario es el siguiente: Valdecarzana: 254, Soto de los Infantes: 97 , La Cabruñana: 12, Quinzanas: 57, Luerces: 53, Muros: 184, Ranón y La Arena: 139, Gúa: 170, Aguino: 63. (Censo de la Corona de Castilla: 1752. Marqués de la Ensenada, vol. II, Madrid, 1991, pp. 230 y ss., 241 y ss., 251 y 266 y ss.)

74. En este sentido, Sancho de Miranda otorgó ordenanzas (en 25 de septiembre de 1566) no sólo para el concejo de Valdecarzana, que era de su jurisdicción, sino que amparándose en ser la Justicia del resto del concejo de Teverga, las hizo extensibles a los tres valles teverganos. El documento fue aprobado y ratificado por los vecinos en 1601, cabe suponer que bajo coacción al ser los titulares de la Casa de Miranda la autoridad judicial. Años más tarde, en 1641 don Sancho de Miranda, I vizconde del Infantazgo impuso nuevas ordenanzas «que se habían de guardar en sus Estados y jurisdicciones». (A.R.I.D.E.A., Casa de Miranda: caja 3, docs. 9 y 12 ) 
Por su parte, los vecinos de los cotos de Muros, Ranón y La Arena contaron con la potestad de poner al juez, pero éste debíó ser previamente designado por el señor. El juez, a su vez designaba «un Merino que actué con apelación», quien aplicaba las condenaciones a favor del titular de los cotos «siendo el dicho nombramiento de merino y apelación al final en perjuicio del rreal patrimonio ${ }^{75}$. Mediado el siglo XVII la justicia del coto de Muros estaba libre de tribunal, excepto de la Chancillería de Valladolid y los Consejos Reales.

En otras ocasiones el noble era comendero o castellano de una fortaleza real. En este sentido los titulares de la Casa de Miranda lo fueron de la fortaleza de San Salvador de Alesga, por la que no parece percibían ninguna contribución ${ }^{76}$. Junto a esta fortaleza ostentaban la Alcaidía del castillo de San Martín de Pravia, situada en la boca de la ría de San Esteban de Pravia ${ }^{77}$. Como tal Alcalde tuvo el derecho a nombrar al capitán del enclave y al capellán de la capilla y como renta jurisdiccional percibía derechos sobre el anclaje en el puerto y el derecho de barquería para el transporte de ribera a ribera ${ }^{78}$. En este caso, don Diego de Miranda, caballero del hábito de Santiago $(† 1632$ ), adquirió por dos vidas la mencionada alcaidía con el derecho de barquería y de presentación del capellán. El oficio fue comprado con derecho de perpetuación por su hijo, don Sancho de Miranda, I marqués de Valdecarzana en $1633^{79}$.

Los Miranda, como hemos visto, concentraron un variado conjunto de jurisdicciones de las que obtuvieron una serie de beneficios en concepto de derechos señoriales. Éstos eran de diversa naturaleza y grabaron sobre varios aspectos, la justicia, la pesca, la tierra, impuestos reales enajenados. En determinados momentos, la Casa de Miranda demandó de sus administradores informaciones sobre los derechos que tenían en ciertos cotos. Una primera evaluación de derechos la solicitó Diego de Miranda c. 1550 con respecto al coto de Soto de los Infantes, información que se demandó de nuevo en 1774. Su sucesor, Lope de Miranda, hace lo propio con los nuevos cotos (Muros, Ranón y La Arena) aportados por su esposa doña Leonor Ponce de León, solicitándose una nueva información sobre Muros y la Alcaidía perpetua de San Martín c. $1650^{80}$. En otras ocasiones no se demandó una información sobre los derechos señoriales, sino que se exige un reconocimiento del señorío y vasallaje por parte de los vecinos de un determinado coto, así sucede en 1766 con los de La Cabruñana ${ }^{81}$.

75. A.R.I.D.E.A., Casa de Miranda, caja 2, doc. 5.

76. Ibidem.

77. Enclave estratégico que se localiza frente al coto de Muros y supone la desembocadura del principal río de la región, el Nalón.

78. A.R.I.D.E.A., Casa de Miranda: caja de arriendos (s/c).

79. Diaz Álvarez, J.: «Aproximación al patrimonio económico...», p. 101; JiMÉnEz ESTRELla, A.: «EI precio de las almenas: ventas de alcaidías de fortalezas reales en época de los Austrias», en Revista de Historia Moderna, 22, 2004, p. 149.

80. A.R.I.D.E.A., Casa de Miranda: caja 2, docs. 5,6 y 7

81. A.R.I.D.E.A., Casa de Miranda: caja 2, doc. 14. 
La posesión de los señoríos llevó parejo otros derechos, que además de ser de tipo económico, repercutieron sobre el sistema de valores y el prestigio social de la época, nos referimos al patronazgo eclesiástico. Ello supuso un doble control sobre los vasallos, que se encontraban sometidos desde el punto de vista económico-político, pero también desde el punto de vista de la mentalidad ${ }^{82}$. La facultad de patronato eclesiástico de presentación de curatos y beneficios la ejercieron en los cotos de Valdecarzana, Taja y Urría (Teverga), Soto de los Infantes (Salas), La Cabruñana y Coalla (Grado), Quinzanas, Muros, Luerces, Ranón y La Arena (Pravia) y Aguino (Somiedo), tal como podemos ver en el Cuadro V.

\subsection{Derechos jurisdiccionales}

Dado el arco cronológico estudiado, observamos un cambio en la percepción de los diferentes derechos jurisdiccionales por parte de la Casa de Miranda. Los ingresos en concepto de señorío no fueron muy altos y podemos decir que su evolución a lo largo del periodo estudiado se mantuvo estancada. El informe de las rentas de c. 1645 no nos informa de las cifras concretas del vasallaje pero por otros documentos sabemos que el coto de Muros pagaba por este concepto 560 reales, cifra que varia de una épocas a otras. Los derechos sobre San Esteban de Pravia suponían 150 reales en las postrimerías del siglo XVIII ${ }^{83}$. Los vasallos de Aguino pagaban en 1756 por el vasallaje 40 reales y los de El Puerto (coto de Gúa) en Somiedo 67,5 reales ${ }^{84}$. La jurisdicción de Valdecarzana satisfacía por su vasallaje tan sólo 30 reales en 1693 y 60 Páramo de Focella por la calidad de comendero del señor de la casa de Miranda ${ }^{85}$.

Junto a estos derechos hay que señalar otros de tipo arcaico, en este sentido se observa los derechos de yantar en las jurisdicciones de Valdecarzana, Taja y Urría,

82. El patronazgo eclesiástico -sin ser ejercido sobre los señoríos, esto es, en parroquias dependiente del realengo- supuso un control de la población por parte de la nobleza al tener el derecho de nombrar a párrocos y beneficiados. Este hecho supone el control indirecto de los vasallos al ser influenciados por los párrocos pues éstos eran nombrados directamente por el señor del coto, por lo que se sobrentiende que eran afines a los dictados del titular. Además de esto estaba el prestigio de la posesión de asientos preeminentes en las iglesias y sepulcros, lo que prestigió a sus poseedores frente al resto del pueblo. [ $\mathrm{Vid}$. MATEO PÉREZ, A.: «La fundación de patronatos: fuente para el estudio de una realidad espiritual, social y artística», en PORRES MARIJUÁN, R. (dir.): Aproximación metodológica a los protocolos notariales de Alava. Edad Moderna, Bilbao, 1986; JARA FUENTE, J. A.: «Muerte, ceremonial y ritual funerario: procesos de cohesión intraestamental y de control social en la alta aristocracia del Antiguo Régimen (Corona de Castilla, siglos XV-XVIII)», en Hispania, 194, 1996, pp. 861-883. Para el caso asturiano vid. CORRIPIO RIVERO, M.: Las capellanías y su relación con Asturias, Discurso de ingreso en la Academia Asturiana de Jurisprudencia, Oviedo, 1981; BARREIRo MALlón, B.: «La nobleza asturiana ante la vida y la muerte», en Actas del II Coloquio de Metodologia Histórica. Historia Aplicada. La documentación notarial, vol. II, Santiago de Compostela, 1984; Díaz Álvarez, J.: «Prestigio social del estamento nobiliario: el patronazgo eclesiástico asturiano de los Vigil de Quiñones en el siglo XVII», en Revista de Historia Moderna, 23, 2003, pp. 261-290.]

83. A.R.I.D.E.A., Casa de Miranda: caja de arriendos: Rentas de los cotos de Muros y Ranón (1785).

84. A.R.I.D.E.A., Casa de Miranda: caja de arriendos: Rentas en el concejo de Somiedo (1756).

85. A.R.I.D.E.A., Casa de Miranda: caja de arriendos: Rentas de la Casa de Miranda (1693). 
Quinzanas, Luerces y Repolles, Ranón y La Arena, Gúa, Caunedo y El Puerto. Era un antiguo privilegio por el que el señor del coto era agasajado con una comida por sus vasallos; con el tiempo derivó en una contribución anual de tipo económica. Este derecho lo observamos ya durante el siglo XVI en Valdecarzana en donde los vecinos debían de aportar entre todos una vaca; en Coalla consistió en el pago de 62 maravedíes por vecino; en Luerces el yantar consistió en el abono de 6 ducados entre todos los vecinos; en Aguino también se satisfizo en dinero y en Gúa éste consistía en la contribución de un carnero y dos vacas o su valor, equivalente a 6.000 maravedíes ${ }^{86}$.

En los cotos que se hicieron solariegos se exigieron contribuciones de fuero que grabaron sobre el suelo. Así, en Coalla en las postrimerías del siglo XVI se exigió el pago de los quiñones, que consistía en el pago de $1 / 5$ de lo que se sembrara y rompiese en los montes y comunales, valorándose en 106 fanegas de escanda en 1592; además el señor exigió el pago de la mitad de lo que produjeran todos los árboles que los vasallos plantaran, así como el pago de la mitad del precio de las casas en las que habitaban. Quiñones también se exigieron en Villanueva y La Mata, que consistieron en un cuarto de lo que se plantara en la vega y 1/5 de los montes; junto a ello pesó en los vasallos una contribución de trabajo personal consistente en la siembra y recogida de la cosecha y de la hierba de los prados del señor, esta contribución aún se observó en los albores del siglo XVIII, percibiendo los Valdecarzana $1 / 4$ de las cosechas, que se valoraban en 30 ducados ${ }^{87}$

Reminiscencias medievales de derechos señoriales se observaron en contribuciones tales como la martiniega consistente en una marrana por vecino en Coalla, un carro de leña y un natalariego (tronco grande de castaño) que debieron ser aportados por los vecinos de Villanueva y La Mata. En Aguino se percibieron tributos de «papas» que consistió en una emina de escanda por vecino, «fosadera» o la contribución de 150 maravedíes por vecino, $\mathrm{y}$ «mortuorio», que grababa a cada vecino que falleciera con el pago del mejor animal que tuviera ${ }^{88}$.

Los derechos de pesquería supusieron un pago por el derecho de aprovechamiento de los recursos pesqueros fluviales; este derecho lo observamos en los cotos de Quinzanas, Luerces y Muros (Pravia), que son atravesados por el río Nalón, reduciéndose a una cuota sobre los salmones pescados durante la primera mitad del año, además de entregar al señor el primer salmón y lamprea de cada temporada ${ }^{89}$.

La posesión de los cotos implicó la percepción de rentas reales, principalmente las alcabalas, que fueron compradas directamente con la jurisdicción o también pudie-

86. FAYA DiAz, M.: A.: Los señorios eclesiásticos..., pp. 69, 71 y 77.

87. lbidem, pp. 69 y 389 .

88. Ibidem, pp. 69 y 77.

89. Este derecho fue pretendido, en otros lugares del concejo de Pravia, de realengo, lo que ocasionó, no pocos problemas entre la Casa de Miranda y el municipio -en el que mantuvieron un importante control político a través de oficios municipales-, derivando en un pleito en 1669, en el que se denunciaron otros abusos por parte del linaje. A.R.I.D.E.A., Casa de Miranda, caja de arriendos: Rentas del I marqués de Valdecarzana (c. 1645); GONZÁleZ-FIERro ORdóÑEZ, F.: Apunte geográfico e histórico..., pp. 28 y s. 
ron haber sido dadas en épocas pasadas como pago a los servicios prestados. De este modo, los Miranda percibieron las alcabalas en los cotos de Soto de los Infantes, La Cabruñana, Quinzanas, Luerces, Muros, Ranón y La Arena. Sus valores no eran excesivos, las de La Cabruñana c. 1645 suponían tan sólo 54 reales $^{90}$. Pero con el tiempo fueron aumentando, lo que dependía del nivel de ventas y de nuevas enajenaciones que se realizaron a lo largo del tiempo, en Muros se percibieron las alcabalas sobre el vino y el saín; en Ranón la del vino, aceite y cestería; en San Esteban la del vino, además de la alcabala de los vecinos; en el caso del coto de Ranón también se percibieron 150 reales anuales sobre la renta de los alfolies ${ }^{91}$.

El señor de Muros cobró también derechos de anclaje a las embarcaciones y un tributo sobre la pesca de salmones, así como parte de los diezmos y las alcabalas ${ }^{92}$. Junto con el vasallaje, los titulares del coto de Muros poseyeron otras propiedades, inmuebles y raíces, que sumaban 520.000 maravedíes hacia $1530^{93}$.

La obtención de los patronatos eclesiásticos de los cotos de su propiedad tiene un interés económico, pues son perceptores de una parte de los diezmos eclesiásticos (vid. Cuadro V). En términos generales la nobleza asturiana fue perceptora de estos derechos eclesiásticos, de hecho en el occidente de la región estos ingresos suponían el $14,8 \%$ en los laicos, por encima de las percepciones de los monasterios ${ }^{94}$. En este contexto, según los libros de Mayores Hacendados del catastro de Ensenada, el marqués de Valdecarzana percibió en este concepto unos 1.235 reales ${ }^{95}$.

Podemos concluir que los derechos señoriales de la Casa de Miranda supusieron un importante aporte a la economía del linaje, que constituyeron según la estimación de las rentas c. 1645, 21.046 reales de vellón ${ }^{96}$. Estos derechos se caracterizaron por la variedad y por ser percibidas principalmente en especie.

\subsection{Rentas sobre la tierra.}

Ser propietario de un coto señorial no significó ser el propietario de todas sus tierras. La titularidad solía implicar la jurisdicción civil y criminal y en el caso de anti-

90. A.R.I.D.E.A., Casa de Miranda: caja de arriendos: Ibidem.

91. La percepción de rentas reales supuso un lucrativo negocio en los señoríos, sobre todo cuando el volumen de ventas (que es lo que grababan las alcabalas) eran considerables, principalmente en el siglo XVIII. Así en el coto de Muros la percepción por vía de alcabalas supuso el $66,70 \%$ de los ingresos del señorío, el $57,71 \%$ en el de Ranón. A.R.I.D.E.A., Casa de Miranda: caja de arriendos: Rentas de los cotos de Muros y Ranón (1785).

92. Hacia 1530 tenía enajenados 27.000 maravedies de rentas reales sobre las alcabalas (Archivo Municipal de Gijón, Fondo Marcenado, Casa de la Rúa, caja 56: Memoria de los bienes del contador Rodrigo de la Rúa y Mencía Fernández de León.)

93. A.R.I.D.E.A., Casa de Miranda: caja 2, doc. 5.

94. FAYA DÍAZ, M." A.; «El occidente de Asturias a fines...», p. 520.

95. FAÝ DÍAZ, M. ${ }^{a}$ A.: «La propiedad nobiliaria en la Asturias del siglo XVIII», en FAYA DÍAZ, M." A. (coord.): La nobleza en la Asturias..., p. 116.

96. Esta cifra supone el $37,72 \%$ de todos los ingresos señoriales y dentro del conjunto de las rentas percibidas el $19,60 \%$. 
guas malaterías eclesiásticas los bienes que les pertenecían directamente. Este hecho hace que los marqueses de Valdecarzana no fueran considerados a mediados del siglo XVIII los mayores hacendados de los cotos de Aguino, Gúa y Caunedo (en Somiedo), Cabruñana (en Grado) y Luerces (en Pravia); en cambio si lo fueron en los señoríos de La Mata y Coalla (en Grado), Muros, Quinzanas, Ranón y La Arena (en Pravia), Soto de los Infantes (Salas) y Valdecarzana (en Teverga) ${ }^{97}$.

A diferencia del sistema señorial del levante peninsular en el que el señor de la jurisdicción era también dueño de la propiedad rústica, en Castilla, incluyendo a Asturias en ella, la cuestión fue diferente. Como hemos dicho jurisdicción y propiedad no siempre iban unidas. A pesar de las influencias de la aristocracia sobre el coto a través del alto bajo mero mixto imperio, que les permitían una serie de abusos, hubo la tendencia a la compra de las propiedades rústicas que aún no estaban a su alcance dentro del mismo coto, por lo que en no pocos casos, a la propiedad jurisdiccional se unió la territorial en un proceso dilatado en el tiempo. Este interés por el incremento de la propiedad rústica dentro de los cotos fue paralelo al que mostraron por otros territorios de la región en los que tenían intereses de tipo político a través de la posesión de diversos oficios municipales.

Las fuentes de las que disponemos para hacer un análisis de la evolución de las rentas y derechos jurisdiccionales percibidos por el marquesado de Valdecarzana para el conjunto de todos los cotos son efímeras. No nos permitirán hacer una trayectoria a lo largo del periodo cronológico planteado en nuestro estudio -aunque sí para determinados señoríos.

Las rentas de los señoríos, tanto las procedentes de derechos jurisdiccionales como las procedentes del arrendamiento de tierras inclusas en los cotos, constituyeron una importante fuente de ingresos para nuestra familia. Si bien es cierto que los ingresos en concepto de vasallaje son con el tiempo irrisorios, el verdadero beneficio se encuentra en derechos varios por los que no se duda pleitear para su defensa frente a agresiones externas ${ }^{98}$.

Hemos de diferenciar, por un lado, los ingresos propiamente señoriales, estos son, los derechos de tipo jurisdiccional, que suponen una carga gravosa para los vasallos, observándose una cierta variedad que depende de la zona en la que se localice el coto; y por otro lado, las rentas sobre las tierras de los cotos, esto es, los ingresos en concepto de arrendamiento o aforamiento de la propiedad rústica o inmueble localizada en los diferentes señoríos.

Las fuentes en las que nos hemos basado no nos permiten hacer una evolución de estos ingresos para todos los señoríos concentrados por los Miranda a lo largo de

97. FAYA DÍAZ, M. ${ }^{*}$ A.: «La propiedad nobiliaria...», p. 111.

98. En 1669 el marqués de Valdecarzana pleiteó con el concejo de Pravia por los derechos que el primero ejerció en diferentes jurisdicciones inclusas en el concejo, refiriéndose principalmente a los derechos de pesquerías, por los que debía recibir los primeros salmones pescados en el río Nalón en cada temporada, asi como la cuota de pesca en mar y barquerías. (GONZÁLEZ-FIERRO ORDÓÑEZ, F.: Apunte geográfico e histórico..., pp. 28 y s.) 
la Edad Moderna. Se tratan de fuentes que nos permiten observar cierta evolución en algunos de ellos en periodos no muy extensos. A pesar de ello, hay un documento de gran importancia. Se trata de un extracto de las rentas del linaje en el Principado de Asturias $^{99}$. El documento ha de ser leído con cautela, pero de gran utilidad, pues nos muestra un mapa de las posesiones a lo largo de la región. Dada la finalidad que tuviera es lógico suponer que las cifras están un tanto abultadas, para darse una mayor importancia; a este hecho hay que añadir la situación de crisis agraria que atravesaba Asturias en la época ${ }^{100}$, por lo que la valoración de los cereales pudo verse alterada, pues el volumen total de rentas percibidas, tanto señoriales como las no señoriales supusieron 107.363 reales $^{101}$, de los que más del $50 \%$ procedían de las jurisdicciones que poseían, concretamente el $51,97 \%$ (vid. Cuadros II y III). El resto de los ingresos procedieron de las propiedades no jurisdiccionales repartidos por diversos concejos asturianos (vid. Cuadro IV), cuya suma fue de 51.577 reales, constituyendo el $48,03 \%$ del total de los ingresos del marquesado.

Los propietarios tendieron a la cesión de sus patrimonios al campesinado a través de contratos de arrendamiento de corto plazo, principalmente cuatro años, en perjuicio de las cesiones a largo plazo que suponía el aforamiento. Así, dentro de los espacios jurisdiccionales las tierras fueron arrendadas produciendo una serie de rentas anuales, rentas señoriales (por proceder de los señoríos) pero nada que ver con los derechos emanados de estos espacios, pues podían arrendarse a vasallos o a cualquier otra persona ajena al coto. Este tipo de rentas fueron valoradas $c$. 1645 en 34.746 reales, lo que suponía un $62,28 \%$ del total percibido en los señoríos (vid. Cuadro III).

\subsection{Abusos señoriales}

Como ya hemos visto hasta ahora el patrimonio señorial acumulado por la Casa de Miranda estuvo plagado de usurpaciones, coacciones, abusos y parcialidades por parte de los titulares. Estos hechos fueron fundamentales para la consecución de los importantes patrimonios económicos que llegaron a concentrar. Estas situaciones se dieron a lo largo de periodo estudiado ${ }^{102}$. Los Miranda habían tomado partido por los

99. Presumiblemente se trata de un documento anexo a un memorial elevado al rey por la familia en los albores de la década de 1640 solicitando la merced de un título de marqués, para lo que harían alarde de los ingresos familjares como acreditación para la obtención de la merced.

100. La década de 1640 no se caracterizó en la región por la abundancia, destacándose en el tramo central una grave crisis que conjugaba una serie de años con una climatología desfavorable dando como consecuencia malas cosechas, por lo que los precios de los cereales se vieron incrementados. (DíAZ ÁLVAREZ, J.: «Crisis agrarias en la Asturias del siglo XVII. Una aproximación a su estudios», en Revista de Historia Moderna, 23, 2005, pp. 311 y s.)

101. Tenemos esta convicción dado que apenas un siglo más tarde, según las informaciones del catastro de Ensenada, las rentas del marquesado de Valdecarzana, en tanto y cuanto mayor hacendado de determinados lugares de la región recibió rentas por valor de 11.760 ducados, siendo el segundo rentista tras el marqués de Santa Cruz de Marcenado. (FAYA DíAZ, M. "A.: «La propiedad nobiliaria...», p. 118)

102. En 1708 el marqués de Valdecarzana y de Rucandío pleitea con la Justicia y Regimiento de la villa de Rucandio (en Cantabria) sobre la pretensión que tenía el marqués de cobrar un foro perpetuo de 800 
Quiñones, lo que les dio lugar a propiciar abusos y tropelías ${ }^{103}$ que les permitieron crear grandes zonas de influencia política, lo que les llevó a enfrentarse al otro bando de la región, los Quirós, cuyos principales seguidores eran los Argüelles y otros linajes menores como los Estrada o los $\mathrm{Nava}^{104}$. Los enfrentamientos de los bandos continuaron durante la primera mitad del siglo XVI, sobre todo por la hegemonía política en la capital del Principado y en el foro político regional, estos son, el ayuntamiento de Oviedo y la Junta General ${ }^{105}$. La rebeldía de los Miranda llegó al extremo de ser desterrados por el corregidor Hernando de Vega por haber protegido a ciertos delincuentes, quizás por ser protegidos del linaje. El destierro había sido impuesto a Diego de Miranda y a su hijo Lope Bernardo en 1496. La corte pidió razones de su proceder al corregidor permitiendo a Diego de Miranda pudiera regresar a Asturias pero no acceder a sus tierras, manteniendo el destierro a su hijo hasta que la causa fuera juzgada por el Consejo Real ${ }^{106}$.

La posición de preeminencia de los Miranda les permitieron acaparar por medios poco ortodoxos diversos lugares, como hemos visto más arriba, con la finalidad de afianzar su poder político y económico. Los abusos de este linaje se extendieron por

maravedies anuales a la villa [A.Ch. V., Pleitos Civiles: Pérez Alonso (Olv.), caja 37.5]. No obstante, se observa un mayor abuso desde el último cuarto del siglo XV al siglo XVI, coincidiendo con la gestación de su patrimonio señorial. En la guerra civil castellana propiciada por la sucesión al trono de Enrique IV se enfrentaron los partidarios de Isabel de Castilla y Juana la Beltraneja, ello se materializó en Asturias a través de la belicosidad de los Quiñones, merinos del Principado, que en no pocas ocasiones se habían enfrentado al poder real aprovechando su debilidad, siendo sustituido su gobierno por la implantación de corregidores. El enfrentamiento de la nobleza regional dio lugar a la creación de bandos, dirigidos por los Miranda y los Quirós, cuando los Quiñones, encabezados por el conde de Luna, fueron apartados de las pretensiones sobre la región, retirándose a León.

103. En este contexto se había enviado a un comisionado-el Licenciado del Campo, juez pesquisidor-desde la corte, en 1485, para que averiguase las razones que había impulsado al corregidor del Principado, Luís Mejía, a poner precio a las cabezas de Diego de Miranda y del conde de Luna, y las penas que pretendía hacer pagar al concejo de Pravia por no haber intentado atrapar a los susodichos. (A.G.S, R.G.S., 148510,53)

104. Desde la corte se insta al corregidor a que haga justicia contre Diego de Miranda y sus partidarios por atentar contra Sancho de Estrada, Suero de Nava y Bernardo de Estrada, procuradores de ciertos concejos en la Junta General en el año 1486. Los enfrentamientos se continúan, incluso produciendo nuertes entre los bandos, pues en 1489 se ordena hacer ejecución contra los bienes y la persona de Gonzalo de Arguelles por haber asesinado a un hijo de Diego de Miranda, se atenta también contra bienes de éstos en el coto de Soto de los Infantes (A.G.S., R.G.S., 148603, 109 y 200; 148908, 275 y 149004, 78). Para observar la situación política asturiana en las postrimerías de la Edad Media y los conflictos armados entre los diferentes bandos vid. AlCEDo, Marqués de: Los Merinos Mayores de Asiurias y su descendencia, Madrid, 1918; URÍA RIÚ, J.: Estudios sobre la Baja Edad Media...; CuARTAs RIVERO, M.: «Los corregidores de Asturias en la época de los Reyes Católicos (1474-1504)», en Asturiensia Medievalia, 2, 1975, pp. 259-278 y Oviedo y el Principado de Asturias a finales de la Edad Media, Oviedo, 1983 Álvarez Álvarez, C.: El condado de Luna en la Baja Edad Media; León, 1980 y «Tenencia de fortalezas asturianas reales por la Casa condal de Luna», en Asturiensia Medievalia, 4, 1981.

105. FAYA DíAZ, M." A.: «Gobierno municipal y venta de oficios en la Asturias de los siglos XVI y XVII», en Hispania, 213,2003 , pp. 78 y ss.

106. A.G.S., R.G.S., 149606, 92. 
varios espacios geográficos de la región, así el concejo de Navia movió pleito contra Lope de Miranda en las primeras décadas del siglo XVI, por sus pretensiones ${ }^{107}$. En otros casos lograron imponerse. En el valle de Candamo pudieron imponer el nombramiento de juez y sus oficiales, lo que propició, en 1492, la realización de una averiguación sobre estos derechos por el corregidor Pedro de Ávila ${ }^{108}$. Posteriormente el corregidor del Principado, Hernando de Vega, solicitó informes sobre los derechos indebidos de los principales nobles de la región: Diego de Quirós y su padre, Diego de Miranda y Bernardo de Quirós, en los concejos de Pravia y de Teverga ${ }^{109}$.

Toda esta problemática se continuó durante la segunda mitad de la centuria. El concejo de Navia volvió a pleitear con los Miranda. En 1577 el concejo, justicia y regimiento de Navia acusó a Leonor Ponce de León y a su marido, Lope de Miranda; a Alonso López de Navia y otros individuos, en tanto y cuanto poseedores de la jurisdicción del concejo de los excesos cometidos por los alcaldes en los juicios de residen$\mathrm{cia}^{110}$. La mayor de las averiguaciones contra las usurpaciones llevadas a cabo por la Casa de Miranda a lo largo del siglo XVI fue llevada a cabo en 1592, cuando se envió a Asturias a un comisionado, el Licenciado Esquivel Dávila, del concejo de Hacienda para hacer la información ${ }^{\prime \prime}$. De ella se observan la coacción, la violencia, la arbitrariedad, contra los vasallos de sus señoríos, así como la usurpación de algunos de ellos. Los vasallos de Coalla acusaron a Diego de Miranda de imponer medidas y precios diferentes a los de la villa de Grado, cabecera del concejo, como solía hacerse en el pasado; también se le acusó de que los vasallos de Coalla, La Mata y Villanueva no pagaran las alcabalas al rey, sino al titular de los cotos; de usurpar la jurisdicción de Repolles y Luerces, so pretexto de que desde su abuelo eran comenderos; de impedir a los vecinos de Quinzanas fueran empadronados por el concejo de Pravia, cabeza del partido de realengo, ni se hiciera en sus vasallos ningún tipo de repartimiento; de usurpar la encomienda de Linares alzándola como coto, y para encubrirlo otorgándolo a Juan de Prada como dote en su matrimonio con Isabel de Miranda (hermana del acusado); así como de actuar contra las leyes del reino al imponer juez en el concejo de Salas, que lo era de realengo.

\section{CONCLUSIONES}

Los Miranda se configuraron como uno de los linajes predominantes dentro de Asturias, abalados por su genealogía, junto con los Quirós. Una acertada política matri-

107. A.Ch.V., Pleitos Civiles: Zarandona y Balboa (Olv.), cajas 1.590-1 y 1.591-1.

108. A.G.S., R.G.S., $149208,86$.

109. A.G.S., R.G.S., 149309, 28.

110. A.Ch.V., Pleitos civiles: Pérez Alonso (F.), cajas 553-1 a 557-1.

111. La Casa de Miranda había sido acusada en 1584 por los principales terratenientes de Teverga: Fabián de Miranda, Diego de Miranda, Estébano de Arguelles y Pedro Vázquez de Miranda, que acusaron a Diego Fernández de Miranda y a su hijo de ejercer la jurisdicción en todo el concejo valiéndose se extorsiones, agravios y malos tratos. (FAYA DiAZ, M." A.: Los señoríos eclesiásticos..., pp. 344 y s.) 
monial, con determinadas familias con intereses económicos en los mismos concejos en los que ellos mismos los tenían, les permitió incrementar su fortuna. Los servicios a la corona, desde el punto de vista administrativo y militar, les permitieron acceder poco a poco a la corte, en la que se insertan, en un primer momento mediado el siglo XVII y permitiéndoles enlazar con miembros de la nobleza titulada cortesana. Este proceso perseguía la finalidad de anexionar diversos mayorazgos y títulos nobiliarios, lo que llegó a su cota más alta en la segunda mitad del siglo XVIII, enlazando con la Grandeza de España y acumulando un total de once títulos nobiliarios en los albores del siglo XIX.

El poder económico de la Casa se basó en la propiedad rústica y en las rentas que de ella emanaron. Desde el punto de vista político se insertaron en la vida administrativa local como regidores de diversos concejos, oficios que adquirieron a través de la enajenación propiciada por los Austrias a mediados del siglo XVI. Por otro lado, fueron asiduos asistentes a la Junta General del Principado, teniéndose noticias de ello desde los últimos años del siglo XV, en calidad de Parientes Mayores del Principado; lo que por otro lado, les permitió también acceder a la corte como legados de la región.

Desde el punto de vista señorial, el marquesado de Valdecarzana se consolidó como la casa asturiana que más jurisdicciones acumuló a través de diferentes medios, no siempre de tipo legal, lo que les permitió el gobierno de unos espacios privados, sustraídos a la autoridad de la Corona, lo que les facilitó el abuso y la obtención de una serie de beneficios económicos, así como un control directo sobre una parte de la población asturiana. Los ingresos de la casa fueron de naturaleza variada, distinguiéndose los ingresos por vía jurisdiccional de los que percibían por vía de derechos jurisdiccionales y rentas sobre la tierra a través del arrendamiento de los bienes de los diferentes cotos. 


\section{APÉNDICE}

\section{CUADRO I: OFICIOS MUNICIPALES DE LA CASA DE MIRANDA}

\begin{tabular}{|c|c|c|c|c|}
\hline CONCEJO & AÑo & OFICIO & COMPRADOR & $\begin{array}{l}\text { PRECIO } \\
\text { (rs) }\end{array}$ \\
\hline \multirow[t]{3}{*}{ Avilés } & 1617 & Regimiento & Lope de Miranda & 825 \\
\hline & 1642 & $\begin{array}{l}\text { Depositaría Gral. de Penas de } \\
\text { Cámara }\end{array}$ & I marqués de Valdecarzana & 1.496 \\
\hline & $\mathrm{s} / \mathrm{d}$ & Alferazgo Mayor & $\mathrm{s} / \mathrm{d}$ & $\mathrm{s} / \mathrm{d}$ \\
\hline \multirow[t]{3}{*}{$\begin{array}{l}\text { Belmonte de } \\
\text { Miranda }\end{array}$} & 1586 & Regimiento perpetuo & Lope de Miranda & 1.210 \\
\hline & 1617 & Regimiento & Lope de Miranda & 551 \\
\hline & 1633 & Regimiento & Sancho de Miranda & 5.720 \\
\hline Castrillón & $\mathrm{s} / \mathrm{d}$ & Regimiento & $\mathrm{s} / \mathrm{d}$ & $\mathrm{s} / \mathrm{d}$ \\
\hline Gijón & $\mathrm{s} / \mathrm{d}$ & Regimiento & $\mathrm{s} / \mathrm{d}$ & $\mathrm{s} / \mathrm{d}$ \\
\hline \multirow[t]{6}{*}{ Grado } & 1591 & 3 Regimientos & Diego de Miranda & $\mathrm{s} / \mathrm{d}$ \\
\hline & 1617 & Escribanía (perpetuación) & Lope de Miranda & 825 \\
\hline & 1619 & Escribanía de Ayuntamiento & Lope de Miranda & $\mathrm{s} / \mathrm{d}$ \\
\hline & 1643 & $\begin{array}{l}\text { 1/3 Procuramiento y Personería } \\
\text { General }\end{array}$ & I marqués de Valdecarzana & 3.300 \\
\hline & $\mathrm{s} / \mathrm{d}$ & Alferazgo Mayor & $\mathrm{s} / \mathrm{d}$ & $\mathrm{s} / \mathrm{d}$ \\
\hline & $\mathrm{s} / \mathrm{d}$ & Escribanía de Número & $\mathrm{s} / \mathrm{d}$ & $\mathrm{s} / \mathrm{d}$ \\
\hline fllas & $\mathrm{s} / \mathrm{d}$ & Regimiento & $\mathrm{s} / \mathrm{d}$ & $\mathrm{s} / \mathrm{d}$ \\
\hline Lena & 1562 & Regimiento & Diego de Miranda & 880 \\
\hline \multirow[t]{3}{*}{ Oviedo } & c. 1599 & Regimiento perpetuo & Diego de Miranda & 11.039 \\
\hline & $\mathrm{s} / \mathrm{d}$ & Regimiento (perpetración) & Lope de Miranda & 2.475 \\
\hline & $\mathrm{s} / \mathrm{d}$ & Tenencia de Regimiento & Don Sancho de Miranda & $\mathrm{s} / \mathrm{d}$ \\
\hline \multirow[t]{7}{*}{ Pravia } & 1617 & Escribanía (perpetuación) & Lope de Miranda & 550 \\
\hline & 1625 & Regimiento & Don Diego de Miranda & 2.573 \\
\hline & 1630 & $\begin{array}{l}\text { Alcaidía del castillo de San } \\
\text { Martín }\end{array}$ & Don Diego de Miranda & 2.200 \\
\hline & 1631 & Regimiento & Don Diego de Miranda & 7.700 \\
\hline & 1631 & Receptoría & Don Sancho de Miranda & 7.700 \\
\hline & 1633 & $\begin{array}{l}\text { Tenencia y Perpetuación de } \\
\text { la alcaidía del castillo de San } \\
\text { Martín }\end{array}$ & Don Sancho de Miranda & 8.800 \\
\hline & $\mathrm{s} / \mathrm{d}$ & Regimiento & $\mathrm{s} / \mathrm{d}$ & $\mathrm{s} / \mathrm{d}$ \\
\hline Salas & 1635 & Regimiento perpetuo & Don Sancho de Miranda & 6.600 \\
\hline \multirow[t]{4}{*}{ Somiedo } & 1558 & Alferazgo Mayor & Sancho de Miranda & 3.300 \\
\hline & 1617 & 2 Regimientos (perpetuación) & Lope de Miranda & 682 \\
\hline & 1620 & Regimiento & Don Diego de Miranda & 6.600 \\
\hline & 1633 & Regimiento & Don Sancho de Miranda & 2.420 \\
\hline
\end{tabular}

112. Con jurisdicción sobre los concejos de Illas y Castrillón. Perpetuación del oficio comprado a Felipe V en 24 de diciembre de 1739 . 


\begin{tabular}{|l|l|l|l|r|}
\hline CONCEJO & \multicolumn{1}{|c|}{ AÑO } & \multicolumn{1}{|c|}{ OFICIO } & \multicolumn{1}{c|}{ COMPRADOR } & \multicolumn{1}{c|}{$\begin{array}{c}\text { PRECIO } \\
\text { (rs) }\end{array}$} \\
\hline & $1635-39$ & 2 Regimientos (perpetuación) & Don Sancho de Miranda & 5.170 \\
\hline & c. 1640 & Regimiento & Vizconde del Infantazgo & 4.191 \\
\hline Tineo & 1633 & Regimiento & Don Sancho de Miranda & 2.420 \\
\hline Babia de Suso & 1585 & Alferazgo Mayor & Lope de Miranda & $\mathrm{s} / \mathrm{d}$ \\
\hline & 1586 & Regimiento & Diego de Miranda & 7.352 \\
\hline & 1638 & Alguacilía Mayor & Don Sancho de Miranda & 3.000 \\
\hline Babia de Yuso & 1586 & Regimiento & Lope de Miranda & 7.352 \\
\hline & 1614 & Regimiento & Diego de Miranda & $\mathrm{s} / \mathrm{d}$ \\
\hline & $\mathrm{s} / \mathrm{d}$ & Alguacilía Mayor & s/d & $\mathrm{s} / \mathrm{d}$ \\
\hline
\end{tabular}

Fuentes: A.R.I.D.E.A., Casa de Miranda, cajas 2 y 3. FAYA DÍAZ, M.a A.: «Gobierno municipal y venta de oficios...», pp. 118-136. * s/d. sin datos.

\section{CUADRO II: DERECHOS SEÑORIALES (C. 1645)}

\begin{tabular}{|c|c|c|c|c|c|c|c|c|c|c|}
\hline Coto & 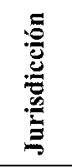 & 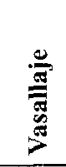 & $\stackrel{\Xi}{\Xi}$ & 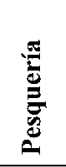 & & 产 & & 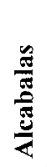 & 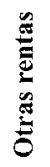 & 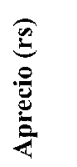 \\
\hline Valdecarzana & SI & - & SI & - & - & - & - & - & SI & 1.266 \\
\hline Taja y Urria ${ }^{113}$ & - & - & SI & - & - & - & - & - & SI & 900 \\
\hline $\begin{array}{l}\text { Soto de los } \\
\text { Infantes }\end{array}$ & SI & - & - & - & - & SI & SI & SI & - & 1.618 \\
\hline Coalla & $\mathrm{SI}$ & - & - & - & - & - & - & - & SI & 1.380 \\
\hline $\begin{array}{l}\text { Villanueva y } \\
\text { Villarruiz }\end{array}$ & - & SI & - & - & - & - & - & - & SI & 2.750 \\
\hline Cabruñana & $\mathrm{SI}$ & - & - & - & - & - & - & SI & - & 54 \\
\hline Quinzanas & SI & - & $\mathrm{SI}^{114}$ & $\mathrm{SI}^{115}$ & - & - & - & SI & $\mathrm{SI}$ & 2.300 \\
\hline $\begin{array}{l}\text { Luerces y } \\
\text { Repolles }\end{array}$ & SI & - & SI & $\mathrm{SI}^{116}$ & - & - & SI & SI & SI & 1.240 \\
\hline Muros de Nalón & $\mathrm{SI}^{117}$ & SI & - & $\mathrm{SI}^{118}$ & $\mathrm{SI}^{119}$ & - & SI & SI & - & 4.600 \\
\hline Ranón y La Arena & SI & - & SI & - & - & - & - & SI & SI & 2.138 \\
\hline
\end{tabular}

113. Se incluyen dentro de Valdecarzana.

114. Derecho a percibir el primer salmón y lamprea de cada temporada.

115. Sobre los salmones.

116. Derecho a percibir el primer salmón y lamprea de cada temporada.

117. Incluye el puerto de mar de San Esteban de Pravia.

118. Derecho a percibir el primer salmón de cada temporada.

119. Derecho de cobro por anclaje sobre los navíos 


\begin{tabular}{|c|c|c|c|c|c|c|c|c|c|c|}
\hline Coto & 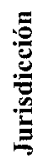 & 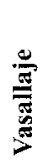 & 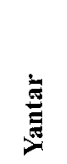 & 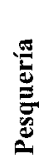 & 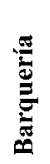 & 离 & $\underset{\mathscr{\Xi}}{\mathscr{\Xi}}$ & 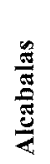 & 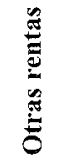 & 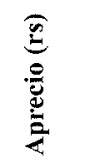 \\
\hline $\begin{array}{l}\text { Gua, Caunedo, } \\
\text { Puerto de } \\
\text { Somiedo }\end{array}$ & S1 & - & $S I^{120}$ & - & - & - & - & - & SI & 1.040 \\
\hline Aguino & SI & - & - & - & - & - & - & Sl & - & 500 \\
\hline Matallana (León) & SI & - & - & - & - & - & - & - & $\mathrm{SI}^{121}$ & 1.260 \\
\hline TOTALES & & & & & & & & & & 21.046 \\
\hline
\end{tabular}

Fuente: A.R.I.D.E.A., Casa de Miranda, Caja de arriendos: Rentas de don Sancho Fernández de Miranda, I marqués de Valdecarzana, c. 1645. * rs. Reales de vellón

CUADRO III: RENTAS SOBRE LA TIERRA (C. 1645)

\begin{tabular}{|l|c|c|c|c|}
\hline \multirow{2}{*}{ Coto } & \multicolumn{2}{|c|}{ Rentas (en especie) } & Otras rentas & Aprecio (rs) \\
\cline { 2 - 5 } & TRIGO (fg) & VINO (cp) & (rs) & 3.312 \\
\cline { 2 - 5 } & 284 & - & - & 720 \\
\cline { 2 - 5 } & - & 30 & - & 1.100 \\
\hline Vajdecarzana & - & - & $1.100^{122}$ & 648 \\
\hline Soto de los Infantes & - & - & - & - \\
\hline Coalla & 516 & - & - & 9.288 \\
\hline Villanueva y Villarruiz & 480 & - & - & 8.640 \\
\cline { 2 - 5 } & - & - & $2.000^{123}$ & 2.000 \\
\hline Cabruñana & - & - & - & - \\
\hline Quinzanas & 148 & - & - & 2.664 \\
\hline Luerces y Repolles & 4 & - & - & 72 \\
\hline Muros de Nalón & 170 & - & - & 2.150 \\
\hline Ranón y La Arena & - & - & 2.000 & 1.152 \\
\hline $\begin{array}{l}\text { Gua, Caunedo y Puerto de } \\
\text { Somiedo }\end{array}$ & 64 & - & - & - \\
\hline Aguino & - & - & - & - \\
\hline Matallana (León) & - & - & - & - \\
\hline TOTALES & - & - & - & 34.746 \\
\hline
\end{tabular}

Fuente: ibidem. * fg. Fanegas; cp. Copas, rs. Reales de vellón

120. Dos yantares.

121. 140 fanegas de cebada.

122. Producción de huertas y prados no arrendados (explotación directa de la Casa de Miranda)

123. Producción de viñas, prados y huertas no arrendados (explotación directa). 
CUADRO IV: RENTAS TERRITORIALES (C. 1645)

\begin{tabular}{|c|c|c|c|c|c|c|c|c|c|c|c|c|c|}
\hline 递 & 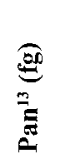 & 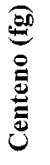 & $\underset{\Xi}{\stackrel{E}{E}}$ & 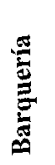 & & 㺃 & 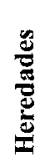 & 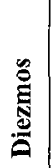 & $\underset{\mathscr{E}}{\stackrel{Q}{E}}$ & 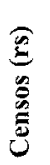 & $\stackrel{\mathscr{E}}{5}$ & $\frac{\pi}{\infty}$ & 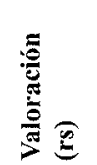 \\
\hline \multirow[b]{2}{*}{ Teverga } & 280 & - & - & - & $\cdot-$ & - & - & - & - & - & - & - & 5.040 \\
\hline & - & - & 60 & $=$ & - & - & - & - & - & - & - & - & 1.680 \\
\hline $\begin{array}{l}\text { Páramo de } \\
\text { Focella } \\
\end{array}$ & - & - & - & - & - & - & - & - & - & $=$ & $\mathrm{Si}$ & - & 66 \\
\hline \multirow[b]{2}{*}{ Oviedo } & - & - & - & - & - & - & - & - & & - & - & - & 117,5 \\
\hline & - & - & - & - & - & - & - & - & - & - & $\mathrm{Si}^{126}$ & - & 600 \\
\hline \multirow[b]{3}{*}{ Avilés } & 78 & - & - & - & - & - & - & - & - & - & - & - & 1.404 \\
\hline & - & - & - & - & - & - & - & - & - & - & - & - & 735,5 \\
\hline & - & - & - & - & - & - & - & - & - & $\mathrm{Si}$ & - & - & 330 \\
\hline \multirow[b]{3}{*}{ Pravia } & 187 & - & - & - & - & - & - & $=$ & - & - & - & - & 3.366 \\
\hline & - & - & - & $\mathrm{Si}$ & - & - & - & - & - & - & - & - & 1.100 \\
\hline & - & - & - & - & $\mathrm{Si}^{128}$ & - & $\mathrm{Si}$ & - & - & - & - & - & $600^{129}$ \\
\hline Miranda & - & - & - & - & - & $\mathrm{Si}$ & $\mathrm{Si}$ & $\mathrm{Si}$ & - & - & - & - & $3.000^{130}$ \\
\hline \multirow[b]{2}{*}{ Salas } & 90 & - & - & - & - & - & - & - & - & - & $=$ & - & 1.620 \\
\hline & - & - & - & - & - & - & - & $\mathrm{Si}$ & - & $\mathrm{Si}$ & - & - & $200^{131}$ \\
\hline \multirow[t]{2}{*}{\begin{tabular}{|l|} 
Grado \\
\end{tabular}} & 200 & - & - & - & - & - & - & - & $=$ & - & - & - & 3.600 \\
\hline & - & - & - & - & - & $\mathrm{Si}$ & - & $\mathrm{Si}$ & - & $\mathrm{Si}$ & - & - & $1.150^{132}$ \\
\hline Somiedo & - & - & - & - & - & - & $\mathrm{Si}$ & $\mathrm{Si}$ & - & - & - & - & $3.240^{133}$ \\
\hline \multirow[t]{2}{*}{ Quirós } & 168 & - & - & - & - & - & - & - & - & - & - & - & 3.024 \\
\hline & - & - & - & - & - & - & - & $\mathrm{Si}$ & - & - & - & $\mathrm{Si}$ & $1.100^{134}$ \\
\hline Llanera & - & - & - & - & - & - & - & $=$ & - & - & $\mathrm{Si}^{135}$ & - & 4.000 \\
\hline $\begin{array}{l}\text { Coto de } \\
\text { Pronga } 136 \\
\end{array}$ & - & - & - & - & $\mathrm{Si}^{137}$ & - & - & - & - & - & - & $\mathrm{Si}$ & $1.400^{138}$ \\
\hline $\begin{array}{l}\text { Yernes y } \\
\text { Tameza }\end{array}$ & - & - & - & - & - & - & - & - & - & Si & - & - & 330 \\
\hline Proaza & 14 & - & - & - & - & - & - & - & - & - & - & - & 252 \\
\hline
\end{tabular}

124. Trigo y escanda indistintamente.

125. El juro estaba cargado sobre los fueros y derechos de la ciudad.

126. Se trata de una casería.

127. Dos juros sobre los alfolíes de la sal, cada uno renta 176,5 y 559 reales de vellón.

128. Cuota sobre los salmones pescados.

129. La cifra no diferencia las contribuciones específicas.

130. Ibidem.

131. Ibidem.

132. Ibidem.

133. Ibidem.

134. Ibidem.

135. Se trata de una herrería. 


\begin{tabular}{|c|c|c|c|c|c|c|c|c|c|c|c|c|c|}
\hline 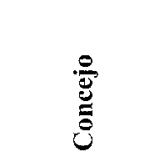 & $\begin{array}{l}\underbrace{00}_{0} \\
= \\
= \\
=\end{array}$ & 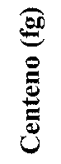 & 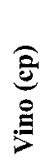 & 离 & 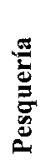 & 焉 & 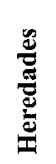 & $\stackrel{8}{:}$ & 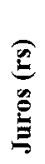 & 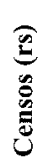 & $\stackrel{\infty}{0}$ & $\frac{\ddot{v}}{\omega}$ & $\begin{array}{l}\frac{5}{8} \\
\frac{\pi}{\pi} \\
\frac{2}{\pi}\end{array}$ \\
\hline \multirow{3}{*}{$\begin{array}{l}\text { Tineo y } \\
\text { Allande }{ }^{139}\end{array}$} & 150 & - & - & - & - & - & - & - & - & - & - & - & 2.700 \\
\hline & - & 150 & - & - & - & - & - & - & - & - & - & - & 1.200 \\
\hline & - & - & - & - & - & - & $\mathrm{Si}$ & - & - & - & - & - & 1.300 \\
\hline \multirow{2}{*}{$\begin{array}{l}\text { Babia de } \\
\text { Suso (León) }\end{array}$} & 27 & - & - & - & - & - & - & - & - & - & - & - & 486 \\
\hline & - & 27 & - & - & - & - & - & - & - & - & - & - & 216 \\
\hline \multirow{3}{*}{$\begin{array}{l}\text { Babia de } \\
\text { Yuso (León) }\end{array}$} & 170 & - & - & - & - & - & - & - & - & - & - & - & 3.060 \\
\hline & - & 176 & - & - & - & - & - & - & - & - & - & - & 1.360 \\
\hline & - & - & - & - & - & $\mathrm{Si}$ & - & $\mathrm{Si}$ & - & - & - & - & $2.600^{140}$ \\
\hline Luna (León) & - & - & - & - & - & - & - & - & - & - & $\mathrm{Si}^{141}$ & - & 700 \\
\hline TOTALES & 1.364 & 353 & 60 & & & & & & & & & & 51.577 \\
\hline
\end{tabular}

Fuente: ibidem. ${ }^{*}$ fg. fanegas, cp. copas, s/e sin especificar, rs. Reales de vellón.

\section{CUADRO V: PATRONATO ECLESIÁSTICO (SIGLOS XVI-XVIII)}

\begin{tabular}{|c|c|c|c|c|c|}
\hline \multirow{3}{*}{ Coto } & \multirow{3}{*}{ Parroquia } & \multicolumn{3}{|c|}{ Presentación } & \multirow{3}{*}{ Diezmo } \\
\hline & & \multirow{2}{*}{ Curato } & \multicolumn{2}{|c|}{ Beneficio } & \\
\hline & & & Curado & Simple & \\
\hline \multirow{2}{*}{ Valdecarzana } & San Pedro de Teverga ${ }^{142}$ & 3 & - & - & $\mathrm{s} / \mathrm{d}$ \\
\hline & San Miguel de la Plaza & - & 1 & - & $\mathrm{s} / \mathrm{d}$ \\
\hline \multirow{2}{*}{ Taja y Urría } & Santo Emiliano de Taja & - & 1 & 1 & $\mathrm{~s} / \mathrm{d}$ \\
\hline & Urría & - & 1 & 1 & $\mathrm{~s} / \mathrm{d}$ \\
\hline \multirow{2}{*}{$\begin{array}{l}\text { Soto de los } \\
\text { Infantes }\end{array}$} & $\begin{array}{l}\text { San Pedro de Soto de los } \\
\text { Infantes }\end{array}$ & 1 & 1 & 1 & $\mathrm{Si}^{143}$ \\
\hline & La Magdalena & - & $\mathrm{Si}^{144}$ & - & $\mathrm{s} / \mathrm{d}$ \\
\hline
\end{tabular}

136. Según el Catastro de Ensenada el coto de Pronga había sido de señorío hasta que sus vecinos se redimieron y se tornaron en los titulares del mismo. (ANES ÁlvareZ DE CASTRILlón, G.: Los señorios asturianos..., p.66)

137. Cuota sobre los salmones pescados.

138. La cifra no diferencia las contribuciones específicas.

139. No se diferencias las rentas de cada uno de los dos concejos.

140. La cifra no diferencia las contribuciones específicas.

141. Rentas sobre praderías.

142. Los Miranda tenían el derecho de presentación del abad de la colegiata de San Pedro de la Plaza, que llevaba pareja una Dignidad del cabildo catedralicio de Oviedo. De forma indirecta, influía en la presentación de las dos dignidades, los veinte canónigos y los 4 racioneros de la abadía presentados por el abad.

143. En 1774 el titular del marquesado de Valdecarzana cobraba la octava parte de los diezmos del curato y la cuarta parte sobre el beneficio simple. (A.R.I.D.E.A., Casa de Miranda, Caja 2, doc. 7: Certificación de los derechos sobre el coto de Soto de los Infantes)

144. No se especifica su número. 


\begin{tabular}{|c|c|c|c|c|c|}
\hline \multirow{3}{*}{ Coto } & \multirow{3}{*}{ Parroquia } & \multicolumn{3}{|c|}{ Presentación } & \multirow{3}{*}{ Diezmo } \\
\hline & & \multirow{2}{*}{ Curato } & \multicolumn{2}{|c|}{ Beneficio } & \\
\hline & & & Curado & Simple & \\
\hline Coalla & San Pedro & - & I & - & $\mathrm{s} / \mathrm{d}$ \\
\hline Cabruñana $a^{145}$ & . & 1 & 1 & - & $\mathrm{s} / \mathrm{d}$ \\
\hline Quinzanas & & - & $51 / 2$ & $51 / 2$ & $\mathrm{~s} / \mathrm{d}$ \\
\hline Muros & & 1 & - & & $\mathrm{Si}$ \\
\hline \multirow{2}{*}{$\begin{array}{l}\text { Ranón y La } \\
\text { Arena }\end{array}$} & Santiago de Ranón & - & \multicolumn{2}{|c|}{$\mathrm{Si}^{146}$} & $\mathrm{~s} / \mathrm{d}$ \\
\hline & San Juan de la Arena & - & \multicolumn{2}{|c|}{$\mathrm{Si}^{147}$} & $\mathrm{~s} / \mathrm{d}$ \\
\hline Aguino & & - & \multicolumn{2}{|c|}{$2 \frac{1 / 2}{148}$} & $\mathrm{~s} / \mathrm{d}$ \\
\hline $\begin{array}{l}\text { Luerces y } \\
\text { Repolles }\end{array}$ & & - & 1 & 2 & $\mathrm{~s} / \mathrm{d}$ \\
\hline Coalla & San Pedro de Coalla & - & 1 & - & $\mathrm{s} / \mathrm{d}$ \\
\hline
\end{tabular}

Fuentes: Ibidem. *s/d. sin datos.

\section{MAPA 1: JURISDICCIONES Y ZONAS DE INFLUENCIA POLITICA DEL MARQUESADO DE VALDECARZANA EN ASTURIAS (SIGLOS XVI-XVIII)}

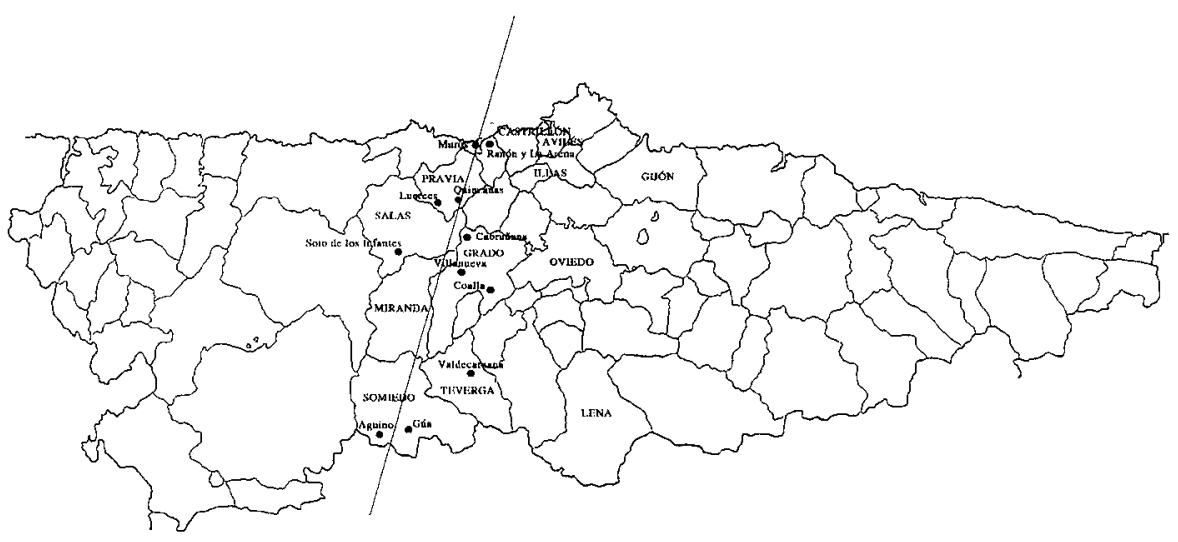

145. Incluye el patronato del hospital de la malatería de San Lázaro.

146. No se identifica su tipo ni número.

147. Ibidem.

148. No se identifica su tipo. 